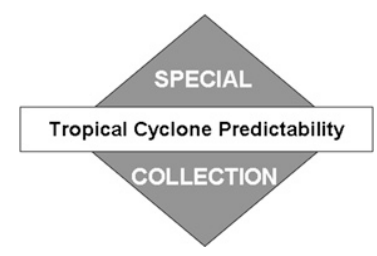

\title{
Intercomparison of Targeted Observation Guidance for Tropical Cyclones in the Northwestern Pacific
}

\author{
Chun-Chieh Wu,* Jan-Huey Chen,* Sharanya J. Majumdar, ${ }^{+}$Melinda S. Peng, \\ Carolyn A. Reynolds, ${ }^{\#}$ Sim D. Aberson, ${ }^{\circ}$ Roberto Buizza, \& Munehiko YAMAGuchi,** \\ Shin-Gan Chen,* Tetsuo NAKAZAwa, ${ }^{++}$and Kun-Hsuan ChOU ${ }^{\# \#}$ \\ * Department of Atmospheric Sciences, National Taiwan University, Taipei, Taiwan \\ + RSMAS Division of Meteorology and Physical Oceanography, University of Miami, Miami, Florida \\ \# Naval Research Laboratory, Monterey, California \\ @ NOAA/AOML Hurricane Research Division, Miami, Florida \\ $\&$ European Centre for Medium-Range Weather Forecasts, Reading, United Kingdom \\ ** Japan Meteorological Agency, Tokyo, Japan \\ $+{ }^{+}$Meteorological Research Institute, Japan Meteorological Agency, Tokyo, Japan \\ \#\# Department of Atmospheric Sciences, Chinese Culture University, Taipei, Taiwan
}

(Manuscript received 19 August 2008, in final form 4 February 2009)

\begin{abstract}
This study compares six different guidance products for targeted observations over the northwest Pacific Ocean for 84 cases of 2-day forecasts in 2006 and highlights the unique dynamical features affecting the tropical cyclone (TC) tracks in this basin. The six products include three types of guidance based on totalenergy singular vectors (TESVs) from different global models, the ensemble transform Kalman filter (ETKF) based on a multimodel ensemble, the deep-layer mean (DLM) wind variance, and the adjointderived sensitivity steering vector (ADSSV). The similarities among the six products are evaluated using two objective statistical techniques to show the diversity of the sensitivity regions in large, synoptic-scale domains and in smaller domains local to the TC. It is shown that the three TESVs are relatively similar to one another in both the large and the small domains while the comparisons of the DLM wind variance with other methods show rather low similarities. The ETKF and the ADSSV usually show high similarity because their optimal sensitivity usually lies close to the TC. The ADSSV, relative to the ETKF, reveals more similar sensitivity patterns to those associated with TESVs. Three special cases are also selected to highlight the similarities and differences among the six guidance products and to interpret the dynamical systems affecting the TC motion in the northwestern Pacific. Among the three storms studied, Typhoon Chanchu was associated with the subtropical high, Typhoon Shanshan was associated with the midlatitude trough, and Typhoon Durian was associated with the subtropical jet. The adjoint methods are found to be more capable of capturing the signal of the dynamic system that may affect the TC movement or evolution than are the ensemble methods.
\end{abstract}

\section{Introduction}

The tropical cyclone (TC) is one of the most threatening natural phenomena that cause great human and economic losses. The lack of observations over the ocean regions where TCs spend most of their lifetime seriously degrades the accuracy of forecasts (Wu 2006). Therefore, it is worthwhile to assimilate the special data

Corresponding author address: Dr. Chun-Chieh Wu, Dept. of Atmospheric Sciences, National Taiwan University, No. 1, Sec. 4 , Roosevelt Rd., Taipei 106, Taiwan.

E-mail: cwu@typhoon.as.ntu.edu.tw obtained from both aircraft (with dropwindsondes deployed) and satellites in areas that may have the maximum influence on numerical model predictions of TCs. To achieve this, several mathematical targeted observing strategies have been developed (Majumdar et al. 2006; $\mathrm{Wu}$ et al. 2007a). The primary consideration in devising such strategies is to identify the sensitive areas in which the assimilation of targeted observations is expected to have the greatest influence on improving the numerical model forecast, by minimizing the analysis error.

Recent research efforts in targeted observations have been associated with the National Oceanic and Atmospheric Administration (NOAA) Winter Storms 
Reconnaissance, NOAA synoptic surveillance, and The Observing System Research and Predictability Experiment (THORPEX). In 2003, the Atlantic Ocean THORPEX regional campaign was launched to improve forecasts of winter cyclones over Europe, using a wider variety of instruments than was possible during the Fronts and Atlantic Storm Track Experiment (FASTEX; Joly et al. 1997) and the North Pacific Experiment (NORPEX; Langland et al. 1999). Several of the objective methods considered previously were used, in addition to more recently developed methods such as Hessian singular vectors (Leutbecher 2003) and observation sensitivity (Langland and Baker 2004). In the Northern Hemisphere summer of 2006, the observation sensitivity and ensemble transform Kalman filter (ETKF; Bishop et al. 2001; Majumdar et al. 2002a) methods were used to provide guidance for deployments of driftsonde balloons traveling across the Atlantic Ocean from their launch site in Africa, as part of the African Monsoon Multidisciplinary Analysis (AMMA). In 2008, targeted observations have been one important facet of the THORPEX Pacific Asian Regional Campaign (T-PARC).

The synoptic surveillance missions to improve TC track forecasts have been conducted by NOAA in the Atlantic basin since 1997 (Aberson and Franklin 1999; Aberson 2002, 2003). In the northwest Pacific Ocean basin, since 2003, Dropwindsonde Observation for Typhoon Surveillance near the Taiwan Region (DOTSTAR) has been conducted under the support of the National Science Council (NSC) in Taiwan (Wu et al. 2005). Four objective methods, adapted from those used to study the winter storms, have been employed for the targeted observations for these surveillance missions of TCs. These products are derived from four distinct techniques. First is the ensemble deep-layer mean (DLM) wind variance of the deep-layer steering flows based on the National Centers for Environmental Prediction (NCEP) Global Ensemble Forecasting System (GEFS), specifically developed for the tropics (Aberson 2003). Second is the ETKF (Majumdar et al. 2002a), which predicts the reduction in forecast error variance for feasible deployment of targeted observations based on a combination of NCEP, European Centre for MediumRange Weather Forecasts (ECMWF), and Canadian Meteorological Center (CMC) ensembles. Third are the total-energy singular vectors (TESVs; Palmer et al. 1998; Buizza and Montani 1999; Peng and Reynolds 2006), which maximize the linear growth of the perturbation total energy in the Navy Operational Global Atmospheric Prediction System (NOGAPS; Rosmond 1997; Gelaro et al. 2002). Fourth is the adjoint-derived sensitivity steering vector (ADSSV; Wu et al. 2007a). By appropriately defining the response functions to represent the typhoon steering flow at the verifying time, ADSSV demonstrates the sensitivity locations at the observing time that would affect the typhoon steering flow at the verifying time. The current ADSSV is calculated based on the fifth-generation Pennsylvania State University-National Center for Atmospheric Research Mesoscale Model (MM5; Grell et al. 1995) adjoint modeling system. In the Atlantic Ocean basin, the TC track forecasts have been improved by $15 \%-$ $20 \%$ within the 5-day forecast period for those missions designed by the targeted strategies (Aberson 2008). In the western North Pacific Ocean basin, an average of $20 \%$ improvement for the $12-72$-h track forecasts over the NCEP Global Forecasting System (GFS), NOGAPS, Japan Meteorological Agency-Global Spectral Model (JMA-GSM), their ensembles, and the Weather Research and Forecasting (WRF) Model has been demonstrated (Wu et al. 2007b; Chou and Wu 2008).

In Majumdar et al. (2006), five targeted observing guidance products based on three different techniques for 2-day forecasts of $78 \mathrm{TC}$ cases during the $2004 \mathrm{At}$ lantic hurricane season were compared. The products include the ensemble DLM wind variance from the NCEP model, two ETKF products based separately on NCEP and ECMWF ensembles, and two TESV products based on ECMWF and NOGAPS. Majumdar et al. (2006) showed that the large-scale characteristics of the ECMWF and NOGAPS TESV guidance products are relatively similar on synoptic scales, but are less similar in the local environment of the TC. For major hurricanes, all techniques usually indicate sensitive regions close to the storms. For weaker TCs, the TESVs only have $30 \%(20 \%)$ similar regions to that from the ETKF (DLM wind variance). The ETKF based on the ECMWF ensemble is more similar to that based on the NCEP ensemble and the DLM wind variance for major hurricanes than for weaker TCs.

Using the same database as Majumdar et al. (2006), Reynolds et al. (2007) identified and interpreted systematic structural differences between these techniques. Their results showed that when the sensitive areas are close to the storm, the TESV presents a maximum in an annulus around the storm, but the ETKF shows a maximum at the storm location itself. When the sensitive areas are remote from the storm, the TESV maxima generally occur northwest of the storm, whereas the ETKF maxima are more scattered relative to the storm location and often occur over the northern North Atlantic.

As a follow-up study, this paper compares six different targeted guidance products based on 84 cases (as described in appendix A) of 2-day forecasts of the northwest Pacific TCs in 2006, and highlights the unique dynamical features that affect the TC tracks in 
TABLE 1. Summary of six targeted methods.

\begin{tabular}{|c|c|c|c|c|c|c|}
\hline $\begin{array}{c}\text { Method } \\
\text { Model }\end{array}$ & $\begin{array}{l}\text { ECSV } \\
\text { ECMWF }\end{array}$ & $\begin{array}{l}\text { NGPSV } \\
\text { NOGAPS }\end{array}$ & $\begin{array}{l}\text { JMASV } \\
\text { JMA/EPS }\end{array}$ & $\begin{array}{c}\text { ETKF } \\
\text { ECMWF NCEP/GEFS CMC }\end{array}$ & $\begin{array}{l}\text { ADSSV } \\
\text { MM5 }\end{array}$ & $\begin{array}{c}\text { NCVAR } \\
\text { NCEP/GEFS }\end{array}$ \\
\hline No. ensemble/SVs & $3 \mathrm{SVs}$ & $3 \mathrm{SVs}$ & $3 \mathrm{SVs}$ & $\begin{array}{l}\text { ECMWF: } 51 \\
\text { NCEP/GEFS: } 60 \\
\text { CMC: } 34 \text { Tot } 154 \text { members }\end{array}$ & - & $\begin{array}{l}14 \text { ensembles }(10 \\
\text { ensembles for } \\
\text { first } 8 \text { cases })\end{array}$ \\
\hline $\begin{array}{l}\text { Resolution of } \\
\text { trajectory }\end{array}$ & T63L40 & T239L30 & T319L40 & $\begin{array}{l}\text { ECMWF: T399L62 } \\
\text { NCEP/GEFS: T126L28 } \\
\text { CMC: } 1.2^{\circ}\end{array}$ & $60 \mathrm{~km}$ & T126L28 \\
\hline $\begin{array}{l}\text { Resolution of } \\
\text { output }\end{array}$ & T63L40 & T79L30 & T63L40 & $2^{\circ}$ & $60 \mathrm{~km}$ & $1^{\circ}$ \\
\hline$t_{i}-t_{a}$ & $48 \mathrm{~h}$ & $48 \mathrm{~h}$ & $48 \mathrm{~h}$ & $66-48 \mathrm{~h}$ & - & $48 \mathrm{~h}$ \\
\hline$t_{a}-t_{v}$ & $48 \mathrm{~h}$ & $48 \mathrm{~h}$ & $48 \mathrm{~h}$ & $48 \mathrm{~h}$ & $48 \mathrm{~h}$ & - \\
\hline
\end{tabular}

this basin. There are six types of guidance: three TESVs from different global models, the ETKF based on the multimodel ensemble members, the DLM wind variance, and the ADSSV (details are listed in Table 1). In the northwestern Pacific Ocean there are several interesting dynamical systems affecting the TC motion (Wu 2006), such as the subtropical high, the midlatitude trough, the subtropical jet, and the southwesterly monsoon. The latter two systems appear to play less significant roles in the Atlantic Ocean. Further analysis is thus conducted to identify the similarities and differences between all these different targeted methods and to interpret their dynamic meanings. The methodologies of the four different techniques and the models adopted are presented briefly in section 2 . Section 3 provides a comparison based on quantitative analyses. Some physical interpretations of the dynamical systems in three special cases are discussed in section 4 . The summary and future prospects are discussed in section 5 .

\section{Targeted observing techniques}

Based on different models and techniques, the six targeted observing products are summarized in Table 1. The three TESV products, called ECSV, NGPSV, and JMASV, respectively, in this study, utilize the first three SVs from three global models, ECMWF, NOGAPS, and JMA/Ensemble Prediction System (EPS). The ETKF method uses multimodel ensemble members. ${ }^{1}$ For the TESV methods, the model initial time $t_{i}$ is $48 \mathrm{~h}$ prior to

\footnotetext{
${ }^{1}$ In this study, 145 ensemble members in total contribute to the ETKF method. Fourteen ensembles and 1 control run of NCEP/ GEFS are calculated from 0600, 1200, 1800, and 0000 UTC, respectively, $66,60,54$, and $48 \mathrm{~h}$ prior to $t_{a}$. In total, 50 ensemble members and 1 control run are from ECMWF initialized $60 \mathrm{~h}$ prior to $t_{a}$. CMC offers 16 ensemble members and 1 control run 60 and $48 \mathrm{~h}$ before $t_{a}$ at 1200 and $0000 \mathrm{UTC}$, respectively.
}

the observing (analysis) time $t_{a}$, while ensemble members of the multimodel forecasts $48-66 \mathrm{~h}$ prior to the observing time are used for the ETKF calculation. The error propagation from $t_{a}$ to the verifying time $t_{v}$ is considered for TESVs and ETKF. The period of $t_{a}-t_{i}$ is selected for planning synoptic surveillance missions, since the decision for aircraft deployment is required at least $36 \mathrm{~h}$ prior to $t_{a}$ in order to meet the air traffic control requirement. For the ADSSV method, the initial condition of the MM5 is based on the 48-h forecast of the NCEP/GFS. The trajectory of $t_{a}$ to $t_{v}$ is then obtained from the MM5 48-h forward integration. The DLM wind variance, also called NCVAR in this study, is calculated based on the ensemble forecast fields of the NECP/GEFS, with 10 bred-mode (Toth and Kalnay 1993) ensemble members before 31 May (for the first 8 cases, as shown in appendix A), and with 14 members based on an ensemble transform technique (Wei et al. 2008) after 31 May. This is a method in which only the period between $t_{i}$ and $t_{a}(48 \mathrm{~h})$ is considered. The resolutions of the trajectory and output of the six methods are also shown in Table 1.

\section{a. TESV}

The SV technique, introduced by Buizza (1994) in the ECMWF ensemble prediction system, and used by Palmer et al. (1998) and Buizza and Montani (1999) to identify targeted observing areas, is a particular type of the general class of targeted analysis error covariance (AEC) optimal. This method was applied to maximize the growth of a total energy perturbation into a forecast verification region for TCs in Peng and Reynolds (2006).

The leading singular vector (SV) represents the fastestgrowing perturbation to a given trajectory (such as a weather forecast) in a linear sense (Peng and Reynolds 2006). The leading SV maximizes the ratio of the final perturbation energy to the initial perturbation energy. 
The second SV maximizes this ratio under the constraint of being orthogonal to the first SV, the third SV maximizes this ratio under the constraint of being orthogonal to the first two SVs, and so on. For complex models such as dynamical TC models, the eigenvector equation may be solved in an iterative fashion using the forward and adjoint propagators linearized about a particular forecast.

The ECSV and NGPSV have been computed using tangent linear and adjoint models of the ECMWF variational data assimilation system (Mahfouf and Rabier 2000) and the NOGAPS forecast system, respectively. Both systems contain surface drag and horizontal and vertical diffusion, but do not include moist processes.

Another SV method, JMASV, contains moist SVs calculated by JMA/EPS, which has been developed using the linearized model and its adjoint version adopted for the JMA global four-dimensional variational analysis system (Yamaguchi et al. 2009). This system consists of full dynamics based on Eulerian integrations and physical processes including representations of vertical diffusion, gravity wave drag, large-scale condensation, longwave radiation, and deep cumulus convection.

\section{b. ETKF}

In this study, the ETKF (Majumdar et al. 2006) uses ensemble-based data assimilation theory (Bishop et al. 2001) to predict the reduction in $200-850-\mathrm{hPa}$ wind forecast error variance within the verification area for feasible deployments of targeted observations, based on 145 ensemble forecast perturbations from three different models (Table 1). As explained in detail in Majumdar et al. (2006), the ETKF computation is a two-stage process. First, the analysis error covariance matrix $\mathbf{P}^{\mathrm{r}}\left(t_{a}\right)$ at the observing time $\left(t_{a}\right)$ pertaining to the routine observational network composed of rawinsondes and satellite-based temperature fields is found by solving the Kalman filter error statistics equation. Next, the analysis error covariance matrix $\mathbf{P}^{q}\left(t_{a}\right)$ for the observational network augmented by the $q$ th hypothetical "test probe" of targeted observations is computed. The test probe comprises targeted observations of $(u, v, T)$ in a $3^{\circ} \times 3^{\circ}$ square lattice, at the $250-, 500-$, and $850-\mathrm{hPa}$ levels. The associated "signal covariance" matrix or reduction in forecast error covariance due to the targeted observations, valid at the verification time $\left(t_{v}\right)$, is then deduced. The trace of this matrix localized within the verification region is referred to in this paper as the "signal variance." The signal variance is then rapidly computed for each different test-probe location on a $1^{\circ} \times 1^{\circ}$ grid. The ETKF guidance then represents this signal variance as a function of the central location of test probes. The test- probe location that produces the highest signal variance is deemed the optimal location for targeting.

\section{c. DLM wind variance}

Using this technique, the sensitive regions at the observing time are represented by locations containing the largest variance of the NCEP/GEFS ensemble of mass-weighted DLM (850-200 hPa) wind (Aberson 2003). Prior to 31 May 2006, the NCEP/GEFS was initialized using bred vectors (Toth and Kalnay 1993). Since 31 May 2006, the ensemble transform (Wei et al. 2008) has been operational at NCEP. The DLM wind is chosen because TCs are generally steered by the environmental DLM flow, and the dropwindsondes from the jet aircraft tend to sample areas in which the uncertainty in this flow is predicted to be the largest. Aberson (2003) demonstrated that the assimilation of only the subset of observations in areas of high NCEP DLM wind variance improved NCEP GFS TC track forecasts more than the assimilation of uniformly sampled observations did.

\section{d. $A D S S V$}

Wu et al. (2007a) proposed ADSSV to demonstrate the sensitivity locations and the critical direction of the typhoon steering flow at the observing time, based on the MM5 adjoint modeling system. The goal of this method is to identify the sensitive areas at the observing time that would affect the steering flow of the TC at the verifying time. The DLM wind within the verifying area is defined as the response function in the MM5 adjoint model. Different from ETKF and SV methods, ADSSV includes a $600 \mathrm{~km}$ by $600 \mathrm{~km}$ square verifying area centered on the MM5-simulated storm location at the verifying time, which is used to calculate the background steering flow. Two responses functions are then defined: $R_{1}$, which is the $850-300-\mathrm{hPa}$ deep-layer area average (Wu et al. 2003) of the zonal component $(u)$; and $R_{2}$, the average of the meridional component $(v)$ of the wind vector.

After being averaged, the axisymmetric component of the strong cyclonic flow around the storm center is removed, and thus the vector of $\left(R_{1}, R_{2}\right)$ represents the background steering flow across the storm center at the verifying time. To interpret the physical meaning of the sensitivity, a unique new parameter, ADSSV is designed. It relates the sensitive areas at the observing time to the steering flow at the verifying time. The ADSSV with respect to the vorticity field (s) is

$$
\mathrm{ADSSV} \equiv\left(\frac{\partial R_{1}}{\partial \varsigma}, \frac{\partial R_{2}}{\partial \varsigma}\right)
$$




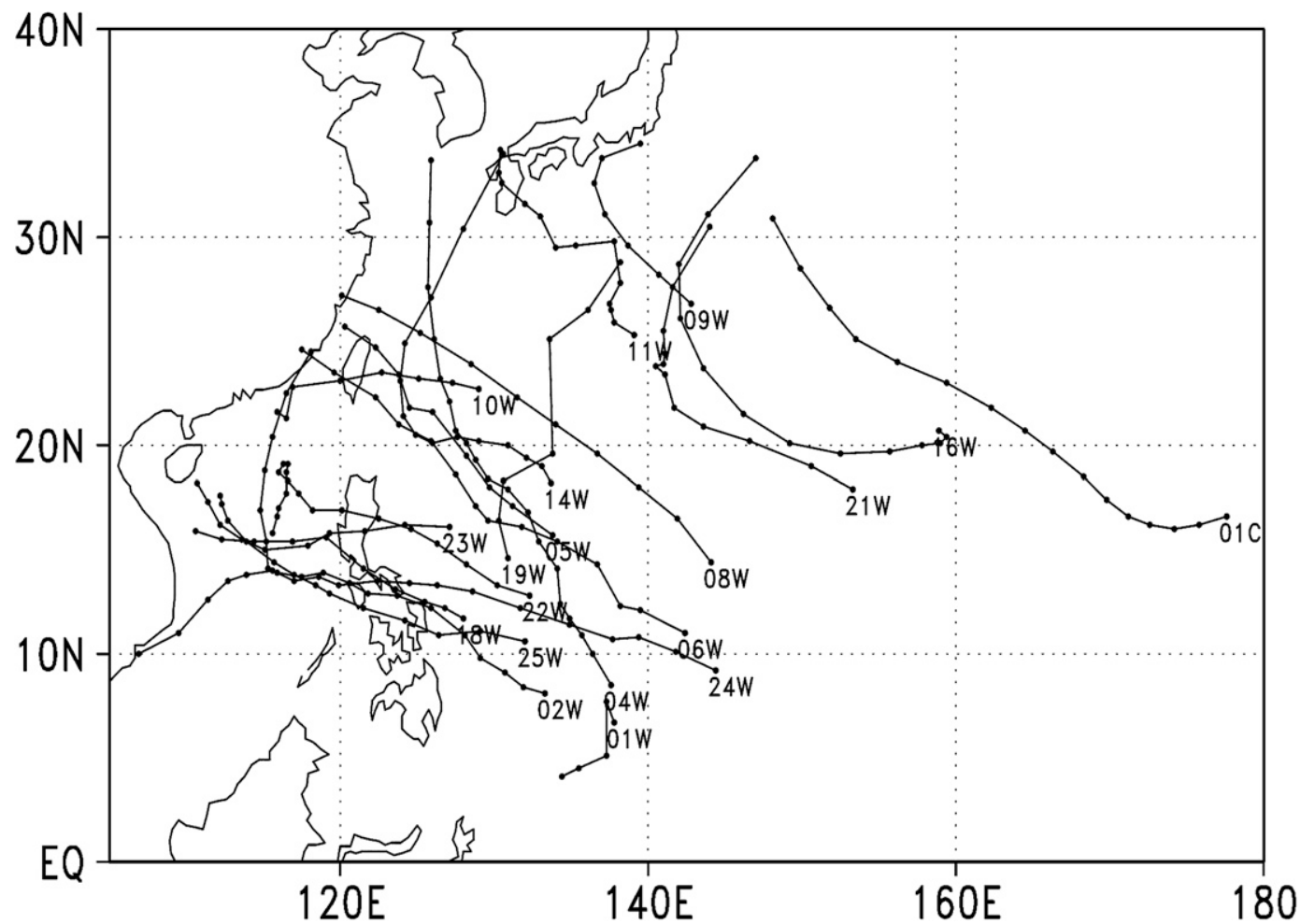

FIG. 1. The JTWC best tracks of the 19 TCs. Each symbol is plotted at 12-h intervals. Except for "01C" (Typhoon Ioke) from the central Pacific, all other TCs are numbered in northwest Pacific orders. For example, " 02 W" is Typhoon Chanchu whose annual cyclone number is 02 in the northwestern Pacific basin in 2006.

where the magnitude of ADSSV at a given point indicates the extent of the sensitivity, and the direction of the ADSSV represents change in the response of the steering flow due to a vorticity perturbation placed at that point. For example, if at a given forecast time the ADSSV vector at one particular grid point points to the east, an increase in the vorticity at this point at the observing time would be associated with an increase in the eastward steering of the storm at the verifying time.

\section{Quantitative comparison}

From the 2006 season, 84 cases in which the Joint Typhoon Warning Center (JTWC) issued forecasts at 0000 UTC and the storms still remained present at $48\left(t_{a}\right)$ and $96\left(t_{v}\right)$ hours were selected for this study (see appendix A). These cases include studies of 19 TCs (Fig. 1), 14 of them made landfall in Japan, Korea, China, Taiwan, Vietnam, and the Philippines. Multiple cases from the same storm are separated by $24 \mathrm{~h}$ on successive days. To be consistent with the work in Majumdar et al. (2006), the verification area is chosen to be centered at the 96-h $\left(t_{v}\right)$ TC position forecast by the JTWC. The values of the six guidance products are interpolated to latitude-longitude $1.5^{\circ}$ grids and normalized by the maximum value of each method for each case. Since the observations collected within the inner three degrees of the TC center generally provide little impact on improving the forecast of TC track (likely because the data were obliterated by the bogus vortex; Aberson 2002), all data within $333 \mathrm{~km}$ of the related model forecast TC center locations $^{2}$ at time $t_{a}$ are ignored. Figure 2 is a representative example to indicate the patterns of the six sets of guidance for a selected case [i.e., number 10 (WP04, Typhoon Ewiniar)]. More details of the targeted patterns for this individual case and the general characteristics are discussed in the following sections. In this section, the two statistical techniques introduced in Majumdar et al. (2006) are used to show the quantitative diversity of the six methods. In this study, we improve upon the statistical techniques of Majumdar et al. (2006) with varying threshold values to elucidate the extent to which two sets of guidance are similar. This allows for a more complete and useful comparison than the results provided in Majumdar et al. (2006). The

\footnotetext{
${ }^{2}$ The TC center information of ETKF at time $t_{a}$ is adopted as the average of the forecast TC center locations weighted by the proportion of the number of ensemble numbers as 6051:34 of NCEP/GEFS, ECMWF, and the CMC model.
} 
\#10 WP04Ewiniar $\mathrm{Ti}=20060702 \mathrm{Ta}=20060704$

(a) ECMWF TESV

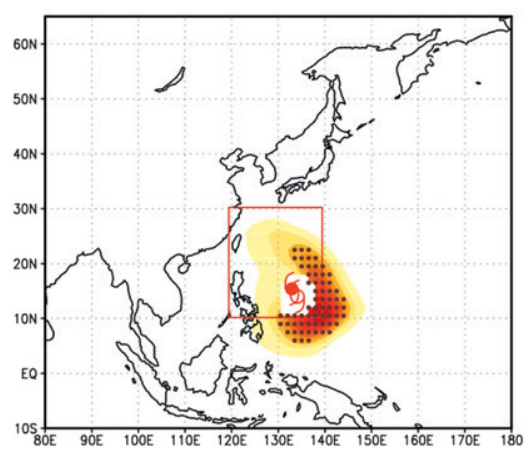

(d) ETKF

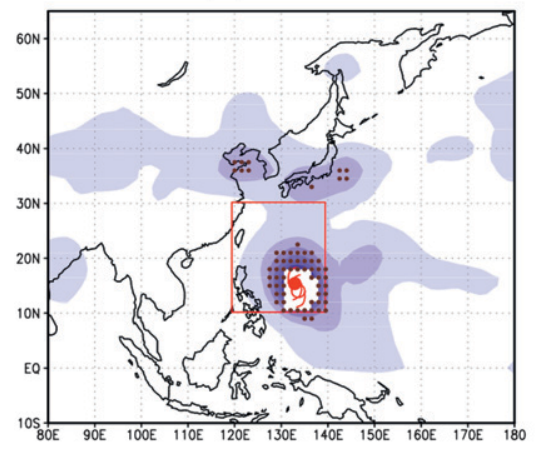

(b) NOGAPS TESV

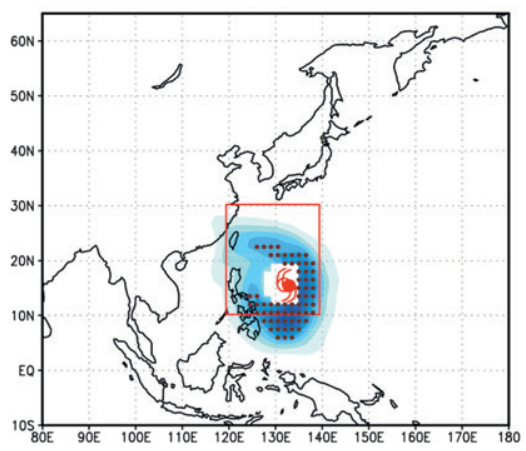

(e) MM5 ADSSV

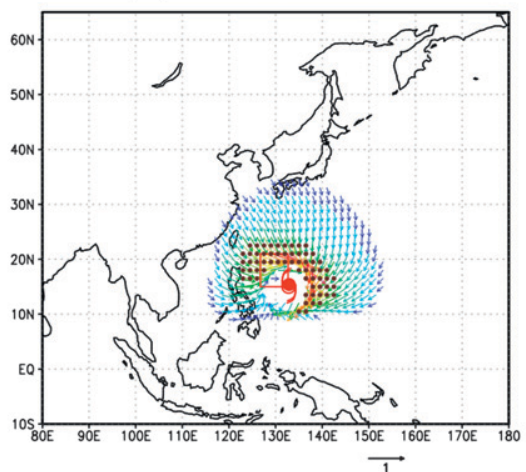

(c) JMA TESV

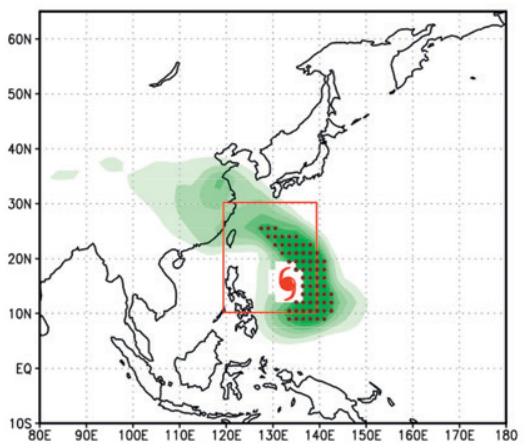

(f) NCEP DLM WIND VARIANCE

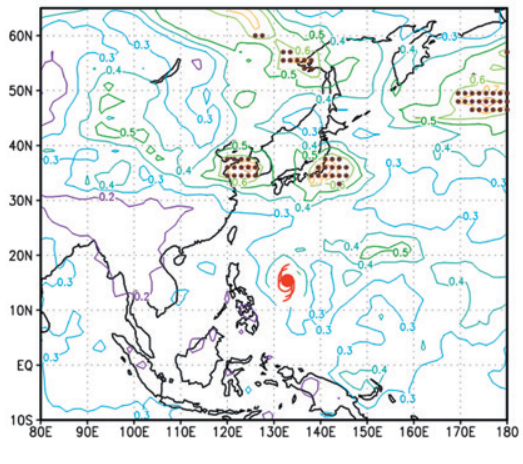

FIG. 2. The large-domain common targeted location comparison of (a) ECSV, (b) NGPSV, (c) JMASV, (d) ETKF, (e) ADSSV, and (f) NCVAR for case 10, Typhoon Ewiniar, at $t_{a}=0000$ UTC 2 Jul 2006 and $t_{v}=0000$ UTC 4 Jul 2006. Except for (f), the verifying areas of the other five methods are indicated by the red squares. The JTWC best track and each model forecast of case 10 valid at $t_{a}$ are denoted by the solid and empty typhoon symbols, respectively. The brown dots represent $X=63$ grid points with the highest value.

statistics here are also compared with the results of Majumdar et al. (2006) for the Atlantic TCs.

\section{a. The common targeted locations}

For each of the 84 cases, there are 15 pairs of maps for the six targeted methods to be compared. In this test, the gridpoint locations corresponding to the number of $X$ highest grid points with leading sensitivity values are first stored for each map and then the number $C$ of the common grid points between each of the 15 pairs are found in each case. A modified equitable threat score (METS; Majumdar et al. 2002b),

$$
\operatorname{METS}=\frac{C-E(C)}{2 X-C-E(C)},
$$

is used to show the commonality between any two maps. In (2), $E(C)$ is the expected number of common grid points, which is estimated between all 84 cases. The first step to obtain $E(C)$ is to compute the 83 values of $C$ between ECSV case 1 and each of NGPSV cases 2-84. The values of $C$ between ECSV case 2 and each of NGPSV cases 1-84, except case 2 are then computed. The procedure is stopped when all $84 \times 83 \mathrm{ECSV}$ and NGPSV cases are computed. Similar procedures are preformed for the other 14 pairs of the targeted methods. The total number of $C$ values for the independent pairs of maps is $N=15 \times 84 \times 83=104580$. The average of the $104580 C$ values is given as $E(C)$ for a fixed $X$. More details of $E(C)$ are introduced in appendix B of Majumdar et al. (2002b). The values of METS for each pair of maps are calculated for each case. When the METS is equal to 1 , the value of $C$ is the same as that of $X$. That means the two maps contain identical targets. A METS greater than (less than) 0 indicates that a larger (smaller) number of common grid points occur than by chance. In the following discussion, the percentage of cases out of 84 in which METS $>0$ (Majumdar et al. 2006) is adopted to show the similarity of the targeted methods. 
TABLE 2. Number of (left) large-domain common grid points $C$ and (right) the corresponding METS for each pair of targeted methods of case 10 (shown in Fig. 2). The METS is computed by (9) with $X=63$ and $E(C)=2.48$.

\begin{tabular}{lccccc}
\hline \hline C/METS & NGPSV & JMASV & ETKF & ADSSV & NCVAR \\
\hline ECSV & $29 / 0.28$ & $44 / 0.52$ & $29 / 0.28$ & $32 / 0.32$ & $0 /-0.02$ \\
NGPSV & & $28 / 0.27$ & $30 / 0.29$ & $27 / 0.25$ & $0 /-0.02$ \\
JMASV & & & $30 / 0.29$ & $37 / 0.40$ & $0 /-0.02$ \\
ETKF & & & & $31 / 0.31$ & $10 / 0.07$ \\
ADSSV & & & & & $0 /-0.02$ \\
\hline
\end{tabular}

To provide a thorough comparison of all the guidance products, following Majumdar et al. (2006), we conduct the comparison based on two domains of different sizes. One is the larger domain $\left(10^{\circ} \mathrm{S}-65^{\circ} \mathrm{N}, 80^{\circ} \mathrm{E}-180^{\circ}\right)$, the other is the smaller domain $(3000 \mathrm{~km}$ by $3000 \mathrm{~km}$ centered at each model storm center). The larger domains tend to highlight the large-scale sensitivity environment (away from the storm), which could be related to the targeting of extra satellite observations (such as rapidscan winds). On the other hand, the smaller domains focus more on the local sensitivity features around the storm region, which is likely more relevant for synoptic surveillance (such as in DOTSTAR)

1) FIXED LARGE DOMAIN $\left(10^{\circ} \mathrm{S}-65^{\circ} \mathrm{N}\right.$, $\left.80^{\circ} \mathrm{E}-180^{\circ}\right)$

A domain containing the northwestern Pacific basin and east Asia's continental region including the Indian Ocean is chosen for the comparison based on METS. In total there are 3149 grid points in this $10^{\circ} \mathrm{S}-65^{\circ} \mathrm{N}$, $80^{\circ} \mathrm{E}-180^{\circ}$ area with $1.5^{\circ} \times 1.5^{\circ}$ resolution. Figure 2 shows the targeted guidance for case 10, Typhoon Ewiniar at $t_{a}=0000$ UTC 2 July 2006. The 63 leading grid points, which is $2 \%$ (this threshold value can be modified, as discussed later) of the total number of grid points, correspond to the sensitive regions $(X=63)$. The value of $E(C)$ is 2.48 under the $2 \%$ threshold mentioned above. In this case, the number of common grid points $\mathrm{C}$ and their corresponding METS for each of the 15 pairs of guidance are listed in Table 2. ECSV versus JMASV has the most common grid points (i.e., 44) and the highest METS value (i.e., 0.52). Both of them show sensitivity within several hundred kilometers to the east of the TC (Fig. 2). On the other hand, NGPSV, ETKF, and ADSSV show high sensitivity near the $\mathrm{TC}$, but with the maximum value in different directions relative to the storm center. As for NCVAR, it does not share common grid points with the three TESVs and ADSSV, while having only 10 common grid points with ETKF.

Table 3 shows the percentages among the 84 cases of those with METS $>0$ for $X=63$. ECSV and NGPSV
TABLE 3. Percentage of the 84 cases in which METS $>0$ for $X=63$ in the large domain.

\begin{tabular}{lccccc}
\hline \hline Methods & NGPSV & JMASV & ETKF & ADSSV & NCVAR \\
\hline ECSV & \multirow{2}{*}{90.48} & 84.52 & 55.95 & 53.57 & 4.76 \\
NGPSV & & 79.76 & 58.33 & 70.24 & 3.57 \\
JMASV & & & 53.57 & 51.19 & 5.95 \\
ETKF & & & & 89.29 & 42.86 \\
ADSSV & & & & & 7.14 \\
\hline
\end{tabular}

are highly similar (METS $>0$ ) in $90 \%$ of the 84 cases. The three TESVs are quite similar to one another, consistent with the results in Majumdar et al. (2006) that the targeted methodology usually gives similar guidance irrespective of the model. The percentage of METS $>0$ for the comparison of ETKF and the three TESVs are around $50 \%-60 \%$. However, the percentage increases to around $89 \%$ when ETKF is compared with ADSSV. For ADSSV, the similarity reaches $70 \%$ when it is compared with NGPSV and around 50\% when compared with the other two TESVs. The similarities between NCVAR and other methods, except the $43 \%$ for ETKF, are generally lower than $10 \%$, indicating that NCVAR persistently shows rather different sensitivity locations as compared with other targeted methods. On the other hand, NCVAR and ETKF usually show sensitivities around the midlatitude jet and extratropical cyclones, which are far from the TCs. Thus, the similarity is higher for this pair than that between NCVAR and other methods.

To explore the similarity of the targeted methods under different TC intensities, according to the SaffirSimpson scale, the 84 cases are divided into 27 major typhoons (MTY; maximum sustained wind $>96 \mathrm{kt}$, i.e., category 3 and above), 38 typhoons (TY; 64-96 kt; categories 1 and 2), and 19 tropical storms (TS; <64 kt). The percentages of METS $>0$ for these three categories are listed in Table 4. The three TESVs have the highest similarities to one another in the TY category. But for the comparison between ETKF and each of the other methods, no specific intensity category shows any particularly higher percentages. Comparing ADSSV to other methods, the highest percentages are identified in the MTY category when compared with ECSV, NGPSV, and ETKF, but in the TY category when compared with JMASV and NCVAR. The agreement of ADSSV versus ETKF reaches $96 \%$ in the MTY category. For the NCVAR method, the highest percentage $(52.6 \%)$ is shown in the TY category when it is compared with the ETKF. On the other hand, the similarity between NCVAR and each of the other methods is very low. The percentages even drop to zero when NCVAR is compared with NGPSV in the TY and TS groups and with 
TABLE 4. As in Table 3, but divided into 27 major typhoons, 38 typhoons, and 19 tropical cyclones of less than typhoon intensity (from left to right).

\begin{tabular}{|c|c|c|c|c|c|}
\hline Methods & NGPSV & JMASV & ETKF & ADSSV & NCVAR \\
\hline ECSV & $88.9 / 92.1 / 89.5$ & $85.2 / 86.8 / 78.9$ & $55.6 / 63.2 / 42.1$ & $55.6 / 55.3 / 47.4$ & $7.4 / 2.6 / 5.3$ \\
\hline NGPSV & & $81.5 / 81.6 / 73.7$ & $74.1 / 60.5 / 31.6$ & $77.8 / 68.4 / 63.2$ & $11.1 / 0.0 / 0.0$ \\
\hline JMASV & & & $55.6 / 60.5 / 36.8$ & $51.9 / 63.2 / 26.3$ & $3.7 / 5.3 / 10.5$ \\
\hline ETKF & & & & $96.3 / 89.5 / 78.9$ & 29.6/52.6/42.1 \\
\hline ADSSV & & & & & $0.0 / 10.5 / 10.5$ \\
\hline
\end{tabular}

the ADSSV in MTY group. In all, the above comparison shows that generally more agreement among the guidance products exists for the stronger storms (MTY and TY) than for the weaker storms (TS). This finding is consistent with the study of the Atlantic TCs (Majumdar et al. 2006), which pointed out that there is a stronger agreement between each comparison pair for major hurricanes than for TCs of weaker intensities.

\section{2) SMALl DOMAIN (3000 BY $3000 \mathrm{KM}^{2}$ ) CENTERED AT EACH MODEL STORM CENTER}

The common targeted locations are also examined in relatively smaller domains in which synoptic surveillance would typically be conducted. A 21 by 21 grid of $150-\mathrm{km}$ resolution is created for every case in a stormrelative coordinate centered at each model storm center. The values obtained from the methods are interpolated linearly onto the grids. Figure 3 shows the targeted guidance in the small domain for case 10 with $X=31$ leading grid points, which is $7 \%$ of total 441 grid points. As mentioned earlier, the sensitivity regions outside of the inner $3^{\circ}$ radius $(333 \mathrm{~km})$ of the storm center are shown. The $E(C)$ is 5.30 for this $7 \%$ threshold. Table 5 contains the numbers of common grid points $C$ and their corresponding METS for each of the 15 pairs for case 10 . The comparison between ECSV and NGPSV shows the highest similarity $(C=20$; METS $=0.4)$, while the comparison between ECSV and JMASV, as well as between JMASV and ADSSV, provides the second highest similarity $(C=18$; METS $=0.33)$. In general, the comparison in the small domain (Table 5) is consistent with that in the larger domain (Table 2). One notable difference is that the similarities of NCVAR versus the three other TESV methods and ADSSV in the small domain (Table 5) are much higher than those in the large domain (Table 2), mainly associated with the leading grid points on the east side of Ewiniar for case 10 in NCVAR (see Fig. 3).

Table 6 shows the percentage of cases with METS $>0$ for $X=31$ among the 84 cases in the small domain. As expected, the three TESV methods are very similar to one another. The percentages of ETKF compared with the three TESV methods are around $45 \%$. The simi- larity between NGPSV and ADSSV is $39 \%$, the same as that between JMASV and ADSSV. The similarity is only $30 \%$ in the comparison between ECSV and ADSSV. Because some of the NCVAR leading grid points are shown to be closer to the storm for the small-domain comparison (i.e., the synoptic surveillance scale), larger similarities for NCVAR versus the TESV methods and ADSSV are found for the small domain than for the large domain. The similarity between NCVAR and ETKF reaches $69 \%$ which is the highest percentage among all 15 pairs in the small-domain comparison. The reason for this result is that the maximum sensitivities are usually around the TCs in both methods on the synoptic surveillance scale. Taking the TC intensity into consideration (table not shown), there is no consistently favorable similarity in any specific intensity categories (MTY, TY, and TS) in the 15 pairs.

\section{3) VARYING THE THRESHOLDS OF THE LEADING GRID POINTS}

To compare our results with those of the Atlantic Ocean, $2 \%(X=63)$ and $7 \%(X=31)$ of the leading grid points are used to calculate the METS in the common targeted location test as in Majumdar et al. (2006) for the large domain and small domain, respectively. To better understand the impact of the threshold values on the results in this test, in this section the comparison between various thresholds of the leading grid points are shown.

The leading grid points $(X)$ vary from $1 \%$ to $10 \%$ of the total 3149 grid points in the large domain, and $1 \%-15 \%$ of total 441 grid points in the small domain. The METS of each of the 15 pairs for each case with respect to different values of $X$ are then computed. Figure 4 shows the percentage (among the 84 cases) of cases with METS $>0$ as a function of the threshold values for the 15 pairs. To show the results more distinctly, the 15 pairs are divided into three groups. In the first group, there are four pairs, three pairs of TESVs and ETKF versus ADSSV, which usually show the high similarity (Figs. 4a,d). The second group contains six pairs for the comparison among ETKF/ADSSV and the three TESV methods (Figs. 4b,e). The third group is for 


\section{\#10 04Ewiniar $\mathrm{Ti}=20060702$ To $=20060704$}

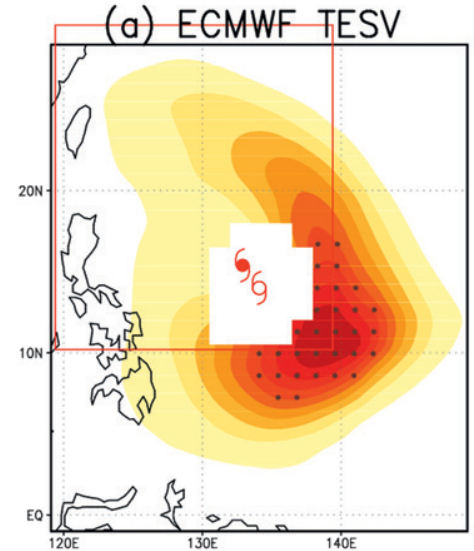

(d) ETKF

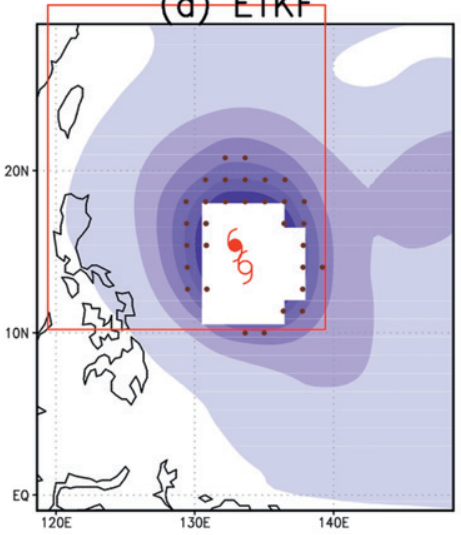

(b) NOGAPS TESV

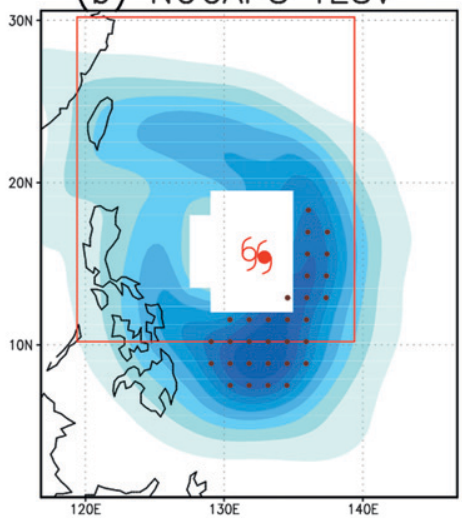

(e) MM5 ADSSV

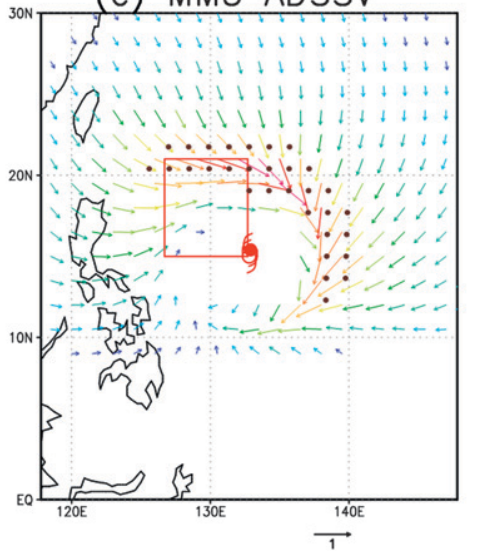

(c) JMA TESV

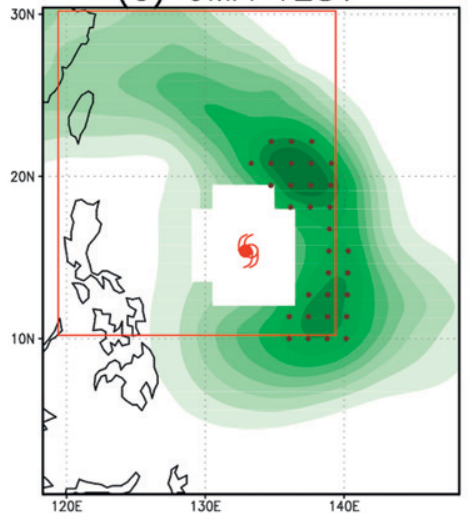

(f)
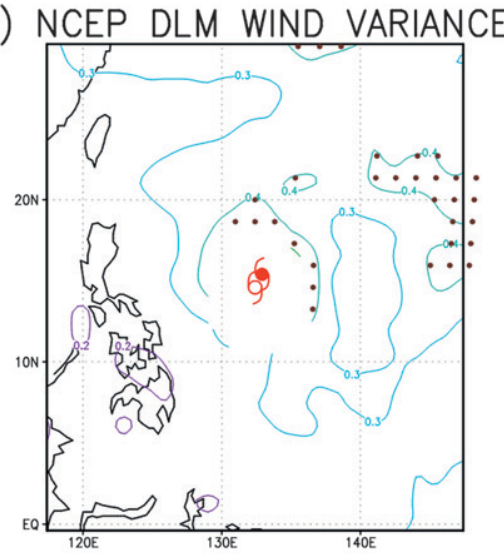

FIG. 3. As in Fig. 2, but for the small-domain common targeted location comparison. The brown dots represent $X=31$ grid points with the highest value.

NCVAR versus the other five methods, which usually shows rather low similarity (Figs. 4c,f). It can be found that as the leading grid points $(X)$ increases, most of the similarity percentages also increase, especially for the second group in both the large and the small domains (Figs. 4b,e), as well as for the first group in the small domain (Fig. 4d). For each of the pairs in the large domain of the first group (Fig. 4a), the similarity percentage remains unchanged for $X$ larger than 3\%. The third group pairs show almost no variation with respect

TABLE 5. As in Table 2, but for the small domain with $X=31$ and $E(C)=5.30$.

\begin{tabular}{lcclll}
\hline \hline C/METS & NGPSV & JMASV & ETKF & ADSSV & NCVAR \\
\hline ECSV & $20 / 0.40$ & $18 / 0.33$ & $9 / 0.08$ & $8 / 0.06$ & $3 /-0.04$ \\
NGPSV & & $10 / 0.10$ & $9 / 0.08$ & $5 /-0.01$ & $3 /-0.04$ \\
JMASV & & & $10 / 0.10$ & $18 / 0.33$ & $4 /-0.02$ \\
ETKF & & & & $13 / 0.18$ & $8 / 0.06$ \\
ADSSV & & & & & $4 /-0.02$ \\
\hline
\end{tabular}

to $X$ (Figs. 4c,f) with the exception of the ETKFNCVAR pair, for which similarities increase with $X$ in the large domain (Fig. 4c).

It can also be found that the three TESVs have the highest similarity among all pairs (Figs. 4a,d). The comparison of ECSV and NGPSV shows that they are the most similar pair while the similarities between ECSV and JMASV, and between NGPSV and JMASV are close in the large domain (Fig. 4a). In the small domain, the comparison of ECSV and NGPSV produces

TABLE 6. As in Table 3, but for $X=31$ in the small domain.

\begin{tabular}{lccccc}
\hline \hline Methods & NGPSV & JMASV & ETKF & ADSSV & NCVAR \\
\hline ECSV & 66.67 & 61.90 & 44.05 & 30.95 & 29.76 \\
NGPSV & & 60.71 & 44.05 & 39.29 & 26.19 \\
JMASV & & & 46.43 & 39.29 & 25.00 \\
ETKF & & & & 51.19 & 69.05 \\
ADSSV & & & & & 21.43
\end{tabular}



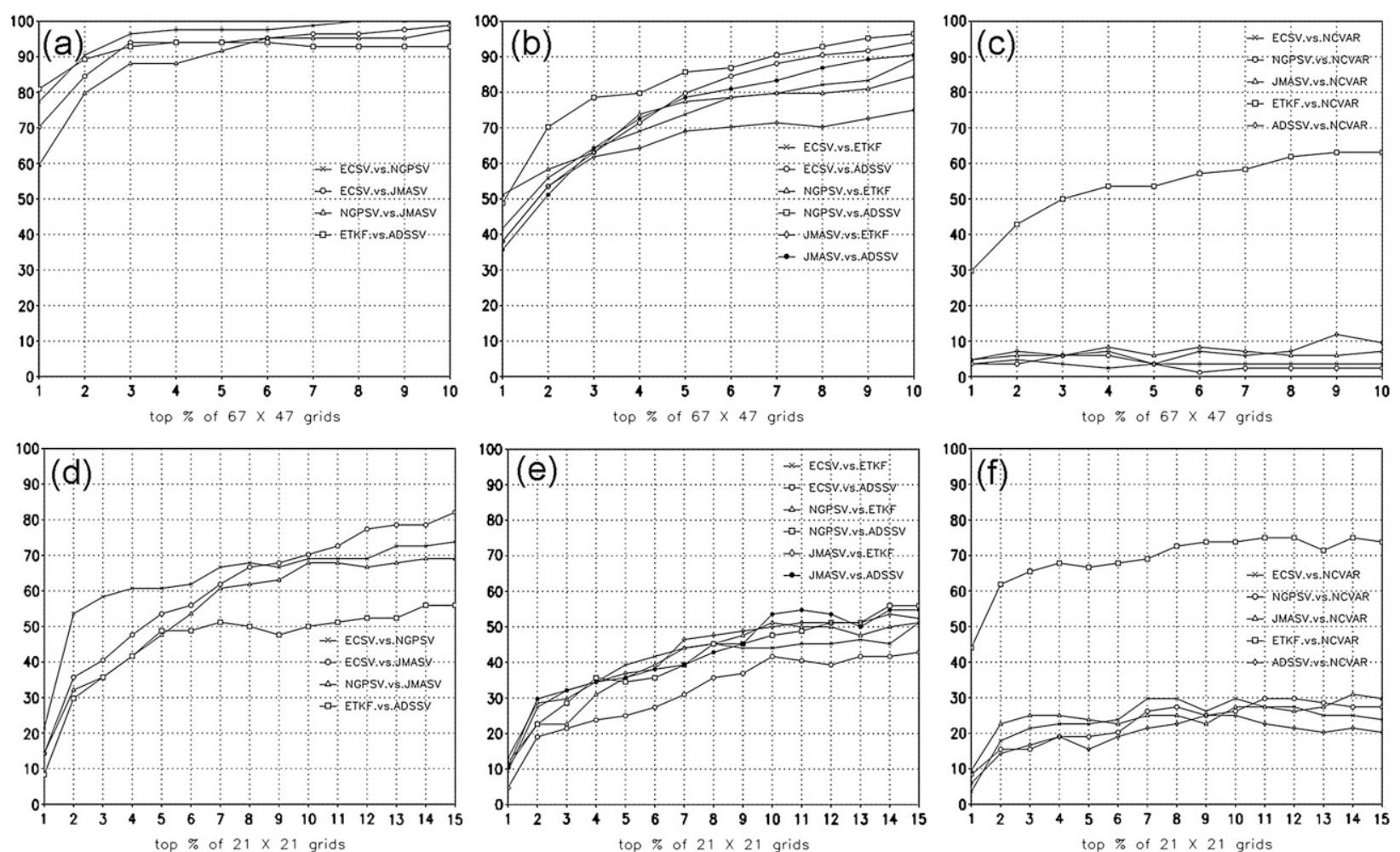

FIG. 4. The ordinate shows the distribution of percentage among the 84 cases with METS $>0$. The abscissa indicates the threshold (a)-(c) from $1 \%$ to $10 \%$ grid numbers of the total $67 \times 47$ grid points in the large domain and (d)-(f) from $1 \%-15 \%$ of the total $21 \times 21$ grid points in the small domain. To show the lines distinctly, the 15 pairs are shown in three groups. (a),(d) The comparison results of three TESVs and ETKF vs ADSSV. (b),(e) The results of ETKF and ADSSV vs the three TESVs. (c),(f) NCVAR vs the other five methods.

the highest similarity when $X$ is below $8 \%$. Beyond $8 \%$, the similarity between ECSV versus JMASV is higher than that between other pairs (Fig. 4d). The comparison of ETKF and ADSSV also shows very high similarity in the large domain (Fig. 4a). In the small domain, besides the comparison between ETKF and ADSSV, the comparison between ETKF and NCVAR also indicates higher similarity (Figs. 4d,f). Note that although ETKF bears some similarity to ADSSV and NCVAR, respectively, the comparison between ADSSV and NCVAR shows very low similarities in both the large and the small domains (Figs. 4c,f). As mentioned above, both ETKF and NCVAR usually show the same sensitivities associated with the midlatitude system far from the TCs in the large domain, which is different to the sensitivity patterns of ADSSV that is closer to the TCs. In the small domain, both ETKF and NCVAR show uniformly distributed patterns surrounding the TCs. However, ADSSV sensitivities occur in different directions for different cases, which are more similar to the sensitivity patterns associated with TESVs. Higher similarities are found between ADSSV and the three TESV products as compared with those between ETKF and the TESV in the large domain when $X$ is larger than 5\% (Fig. 4b). Note that the comparison of ADSSV and ECSV shows less similarity than that of other pairs in the small domain (Fig. 4e).

Regarding the similarity under different TC intensities (MTY, TY, and TS; figures not shown), the similarities for the second group decrease as the intensity is reduced. However, this feature is not obvious in the first and third groups. In the first group, the comparison of ETKF and ADSSV shows the highest similarity (which reaches $100 \%$ ) when the threshold is higher than $3 \%$ in the MTY category, with lower similarities in the TY category and much lower similarities in the TS category for the large domain. In the small domain, most of the results in the three intensity categories are consistent with that of all 84 cases as discussed above.

\section{b. Ranking of neighboring regions}

Following Majumdar et al. (2006), another rankingbased statistical technique is employed for this intercomparison study. This method, based on a Spearman ranking, provides a separate means to compare the ranks of potential target areas around the storm. To 


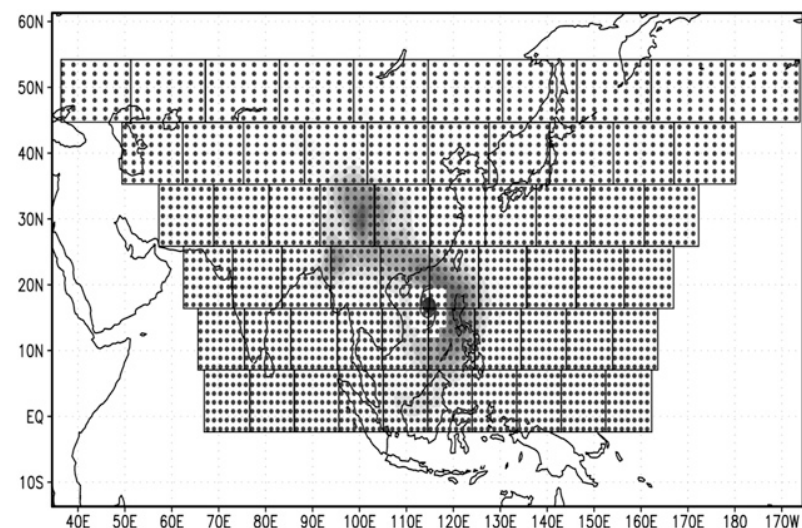

FIG. 5. Regions to be ranked for NPGSV for case $7\left(t_{a}=\right.$ 0000 UTC 16 May 2006) in the large domain. Each of the $Y=60$ square regions are plotted while each region consists of $7 \times 7$ grid points at $150-\mathrm{km}$ resolution.

conduct the ranking, $Y$ adjacent geographical regions in each targeted method are first set. The distance between each region is set at $1050 \mathrm{~km}$ (see appendix B for details), thus each region represents a square of equal area of $7 \times 7$ grid points with $150-\mathrm{km}$ resolution (boxes in Figs. 5 and 6). Comparisons are also performed in the large and small domains. For example, Figs. 5 and 6 show $Y=60$ and $Y=16$ square regions in storm-relative coordinates for the large and the small domains, respectively. For each of the 84 cases, the average value of each method within each region is computed, and these regions are ranked from the first to the $Y$ th. The degree of similarity between any two methods is then computed via the Spearman rank correlation coefficient $\left(R_{s}\right.$; Wilks 1995) for that case.

\section{1) LARGE DOMAIN}

In the large domain, for each case, $Y=60$ square regions are set around the storm as in Fig. 5. The whole domain contains five regions to the west and to the east side, four regions to the north, and two to the south of the storm center. Figure 7 shows the percentage of cases (out of the 84 cases) in which the Spearman rank correlation coefficient $\left(R_{s}\right)$ of the rankings between any set of two targeted methods are larger than 0.0, 0.2, and 0.5. When $R_{s}>0.0$ is used as the threshold (following Majumdar et al. 2006), most of the pairs show high percentages (except for comparisons involving NCVAR), all of which exceed $80 \%$, while most exceed $90 \%$. Comparing this finding with that in Majumdar et al. (2006), which also uses the same threshold of $R_{s}>$ 0.0 , but with percentage ranging roughly between $8 \%$ and $100 \%$, the comparison based on the ranking of neighboring regions shows that the targeted methods

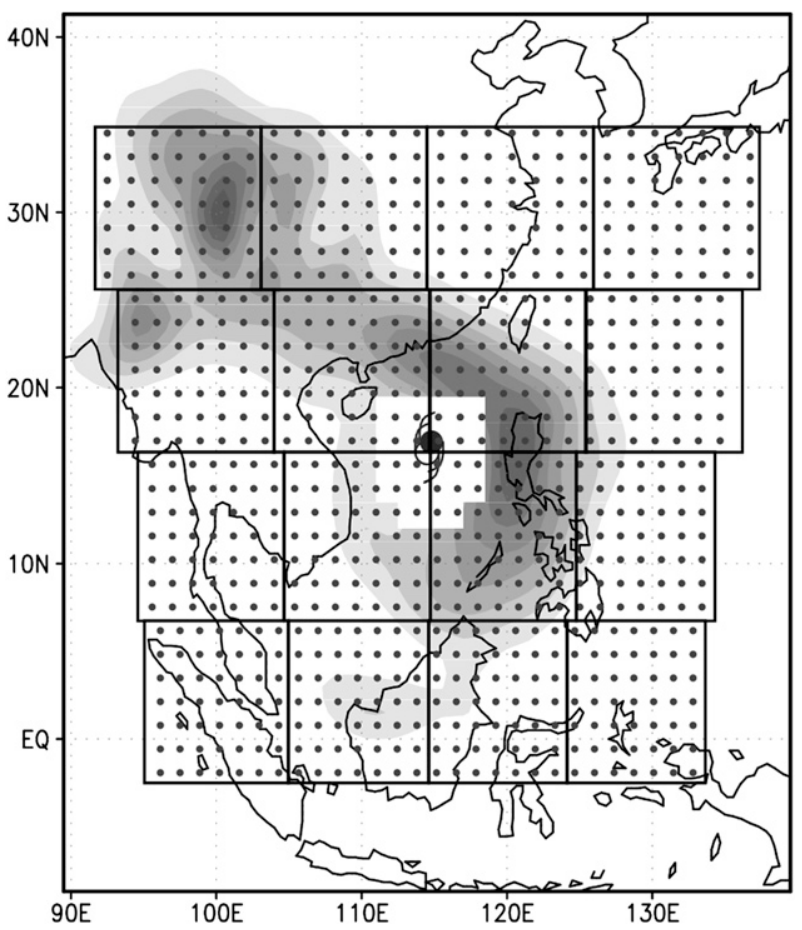

FIG. 6. As in Fig. 5, but for $Y=16$ for the small domain.

applied to northwestern (NW) Pacific typhoons studied here have higher similarity than those applied to Atlantic storms.

To better distinguish the similarity of the 15 pairs of targeted methods, we also examine the statistics based on two higher thresholds (i.e., $R_{s}>0.2$ and $R_{s}>0.5$ ). The comparison of ECSV and NGPSV shows similar rankings in all cases (i.e., 100\%) for both thresholds of $R_{s}>0.2$ and $R_{s}>0.5$. Overall, for both $R_{s}>0.2$ and $R_{s}>0.5$ thresholds, high similarities are shown in the comparison among the three TESVs. Regarding the comparison of the three TESVs with ETKF and ADSSV, Fig. 7 shows that JMASV is more similar to ETKF than to ADSSV, while the similarities in the comparisons of the other two TESVs to ADSSV are higher than to ETKF when the threshold is $R_{s}>0.2$. Under the same threshold, the ETKF-NCVAR pair shows high similarity $(70 \%)$ while the similarity for the ETKF-ADSSV pair is around $37 \%$. Note that unlike the results of common targeted location test, the comparison between ETKF and ADSSV does not show very high similarity. When the threshold is $R_{s}>0.2$, the similarity between these two methods is much lower than the comparisons of either one to the three TESVs. The comparisons between NCVAR and other target methods still show low similarities, except when compared with ETKF. It is interesting that the comparison between NCVAR and JMASV shows much higher 


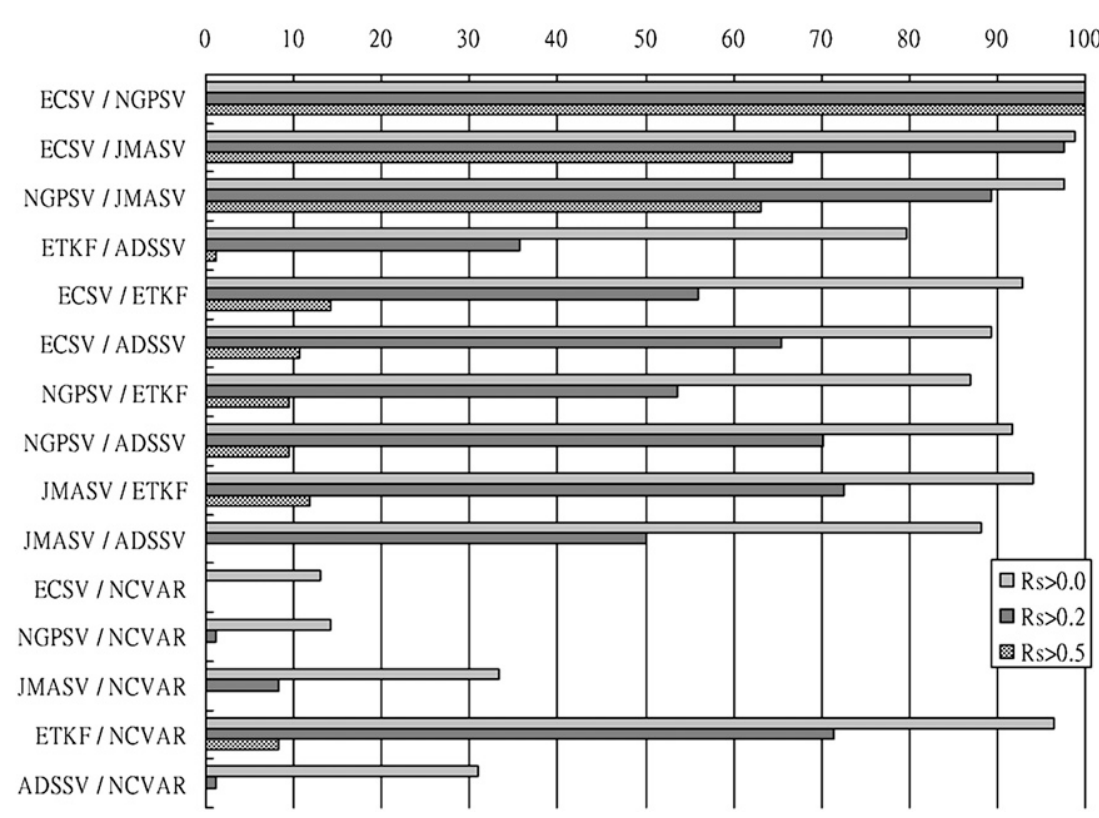

FIG. 7. Percentage of cases in which the Spearman rank correlation coefficient $\left(R_{s}\right)$ of the rankings between any set of two methods are larger than $0.0,0.2$, and 0.5 for the large domain.

similarity than that between NCVAR and ADSSV and other TESVs. This may correspond to the high similarities of both ETKF versus JMASV and ETKF versus NCVAR.

To further assess the dependence of the similarity among the guidance products on TC intensity, Fig. 8 shows the percentage of 27 major typhoons (MTY), 38 typhoons (TY), and 19 tropical storms (TS) cases with the threshold of $R_{s}>0.2$. It can be found that most of the pairs show that the TS category usually has lower similarity than the stronger groups, except for the ETKFECSV and JMASV-NCVAR pairs. The 5\% similarity

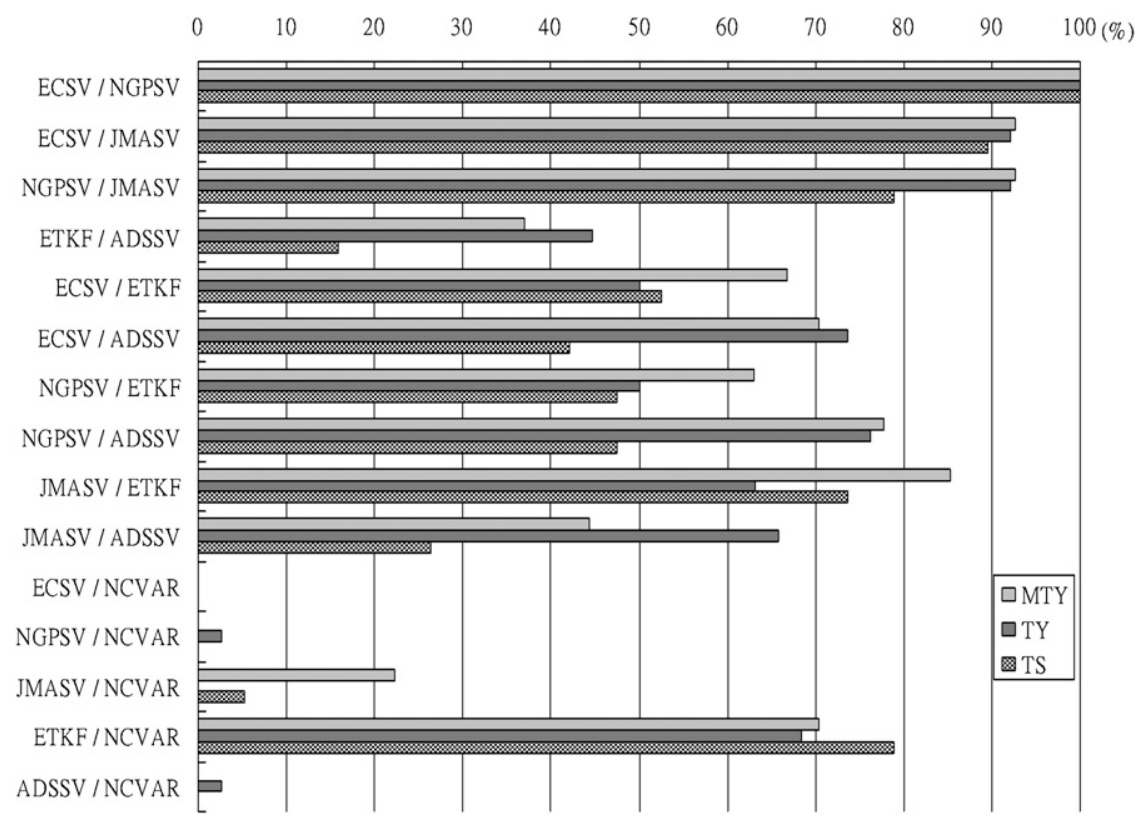

FIG. 8. Percentage of cases with the Spearman rank correlation coefficient $\left(R_{s}\right)$ set to be larger than 0.2. Results are shown for typhoons of three different intensity categories: 27 major typhoons (MTY), 38 typhoons (TY), and 19 tropical cyclones (TC). 


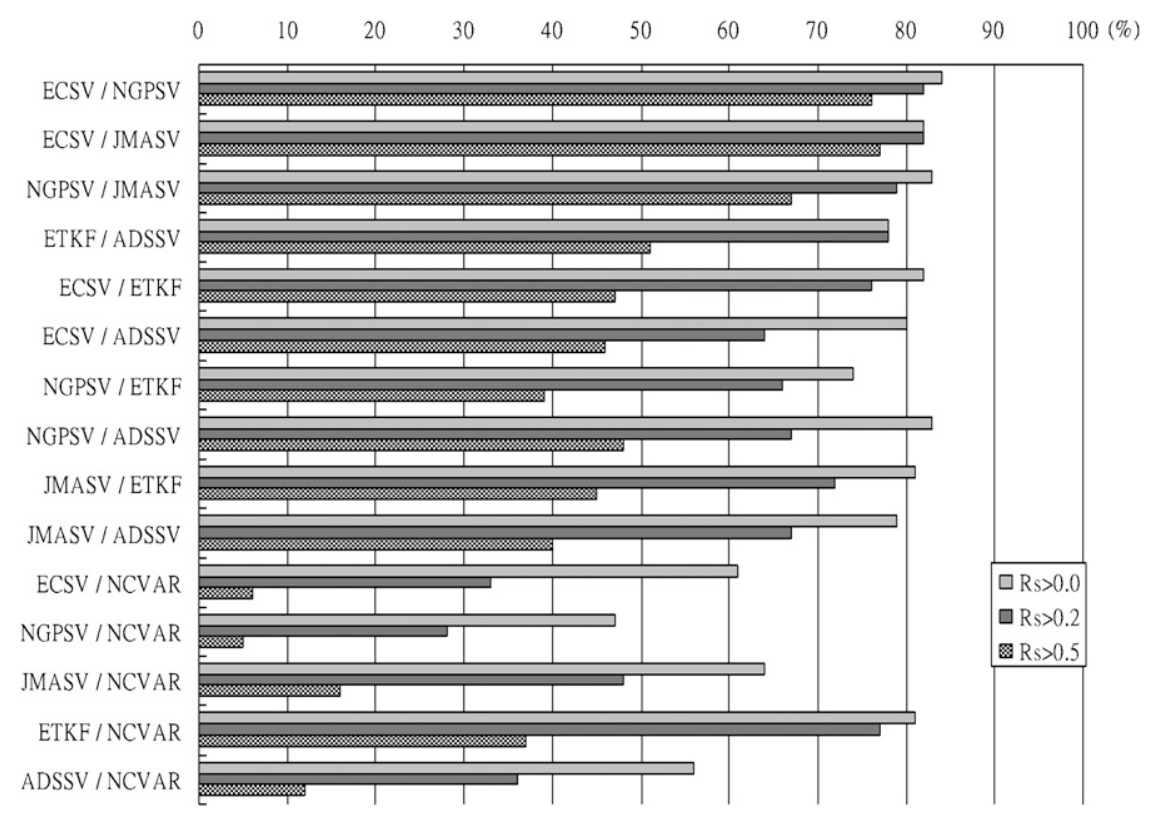

FIG. 9. As in Fig. 7, but for the small domain.

between JMASV and NCVAR in the TS category may reveal that the higher similarity between JMASV and NCVAR mentioned above is mostly contributed by the weaker cases.

\section{2) SMALl DOMAiN}

The domain is reduced to $Y=16$ (Fig. 6) for the synoptic surveillance mission application. From Fig. 9, it can be found that a higher threshold $(R s>0.5)$ is needed to better distinguish the similarities among the 15 pairs in the small domain than in the large domain (i.e., $R_{s}>0.2$ ). When the threshold is $R_{s}>0.5$, it shows that the comparisons among the three TESVs have the highest similarities (over 65\%), while the comparison between ETKF and ADSSV also show a high similarity of around $52 \%$. The first four most similar pairs are consistent with the results of common targeted locations in the large domain. Among the six pairs of ETKF and ADSSV to the three TESVs, ADSSV and NGPSV shows the highest similarity (around 48\%). Meanwhile, the similarity associated with the comparisons between ETKF and either ECSV or JMASV is higher than that between ADSSV and either ECSV or JMASV. For the comparisons of NCVAR with other methods, as previously discussed, the highest similarity is shown for the ETKF-NCVAR pair. The comparisons of both JMASV and ADSSV with NCVAR show low percentages of $16 \%$ and $12 \%$, while a percentage even lower than $8 \%$ is shown in the comparison between NCVAR and both ECSV and NGPSV.

\section{Discussion of some representative special cases}

As pointed out earlier, more dynamical systems (such as the midlatitude trough, the subtropical jet, the southwesterly monsoon, and binary interactions) may affect the TCs in the NW Pacific Ocean than those in the Atlantic Ocean. In this section, three special cases are analyzed to highlight the similarities and differences between different targeted methods and to interpret the dynamic meanings.

\section{a. Case 2-Affected by the subtropical high}

Figure 10 shows the sensitivities of the six targeted methods superposed with the geopotential height field in the NCEP final analysis $\left(\mathrm{FNL} ; 1^{\circ} \times 1^{\circ}\right)$ at $500 \mathrm{hPa}$ of Typhoon Chanchu, with 0000 UTC 11 May as the observing time ( $t_{a}$; case 2$)$. The zonal region of the subtropical high extends from $100^{\circ}$ to $150^{\circ} \mathrm{E}$, as indicated by the 5880 -gpm contour, and the TC is located at $10^{\circ} \mathrm{N}$, $128^{\circ} \mathrm{E}$, which is just at the edge of the subtropical high. Among the six guidance products, the three TESVs and ADSSV show similar sensitivity results. Namely, major sensitivities occur at about $500 \mathrm{~km}$ around Chanchu, though at different directions relative to the storm center. In general, the main sensitivities among the above four methods are located to the east of the storm center. Furthermore, ECSV and NGPSV show sensitivities to the south of the storm center, and NGPSV, JMASV, and ADSSV show sensitivities around the north to the northeast part of the storm. Note that these sensitivities are associated with the subtropical high. In 


\section{\#02 WP02Chanchu $\mathrm{Ti}=20060509 \mathrm{Ta}=20060511$}

(a) ECMWF TESV

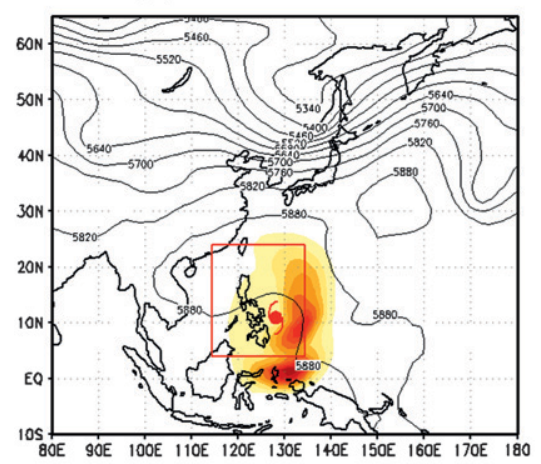

(d) ETKF

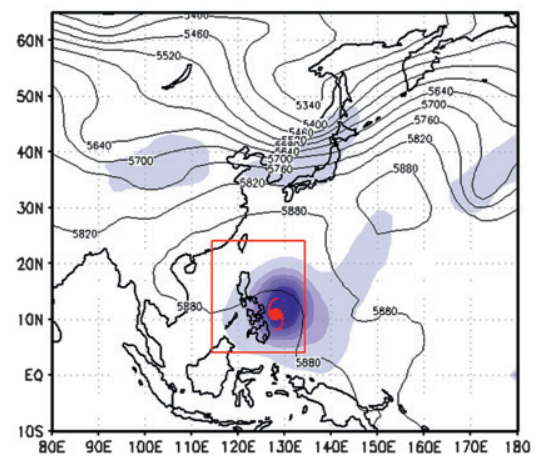

(b) NOGAPS TESV

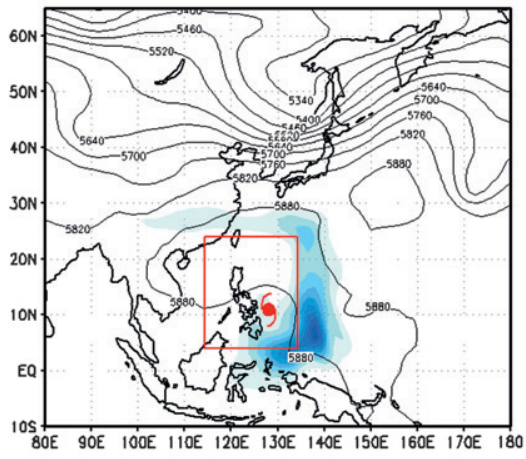

(e) MM5 ADSSV

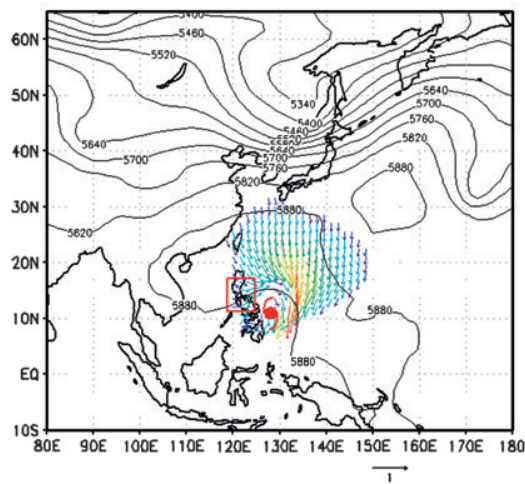

(c) JMA TESV

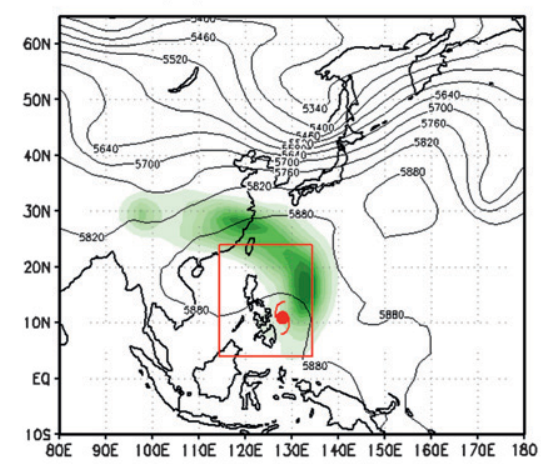

(f) NCEP DLM WIND VARIANCE

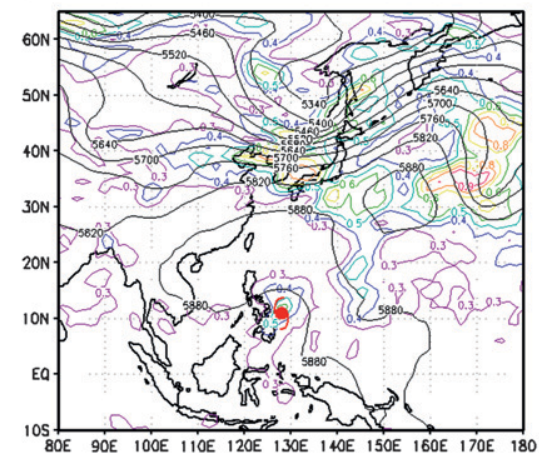

FIG. 10. The sensitivities of (a) ECSV, (b) NGPSV, (c) JMASV, (d) ETKF, (e) ADSSV, and (f) NCVAR superposed with the geopotential height field (contour interval of $60 \mathrm{gpm}$ ) from NCEP FNL at $500 \mathrm{hPa}$ of case 2, with 0000 UTC 11 May as the observing time $\left(t_{a}\right)$. The verifying areas of the other five methods are shown as the red squares in (a)-(e). The JTWC best track at $t_{a}$ is denoted by the solid typhoon symbols.

general, locations with highest sensitivity collocate well with the border between the TC and the subtropical high in Figs. 10a,b,e. It can be assumed that the sensitivity results show the impact of the steering flow from the subtropical high on the TC movement. In contrast, in addition to the large values at the storm center, ETKF also shows sensitivity associated with midlatitude troughs north and the northeast of the TC. For NCVAR, the high sensitivity is located at the TC center and the midlatitude trough far away from the TC, which appears to have no physical link to the storm motion.

\section{b. Case 38-Affected by the midlatitude jet}

Case 38 is Typhoon Shanshan with 0000 UTC 16 September as the observing time $\left(t_{a}\right)$. The midlatitude trough played an important role in affecting Shanshan's track when it recurved from westward to northward and northeastward later in its life cycle (Wu et al. 2009). In
Fig. 11, the NCEP FNL geopotential height field shows that the midlatitude trough is located around $20^{\circ}-40^{\circ} \mathrm{N}$, $115^{\circ}-120^{\circ} \mathrm{E}$, while the $\mathrm{TC}$ is at $26^{\circ} \mathrm{N}, 123^{\circ} \mathrm{E}$. Figures $11 \mathrm{a}-\mathrm{c}$ show that the adjoint methods (three TESVs) produce high sensitivities at the center and the upstream region of the trough, while the ADSSV shows high sensitivity right at the trough location (Fig. 11e). On the other hand, the ensemble methods (ETKF and NCVAR) show some sensitivity downstream of the trough, while the maximum sensitivity is still located around the TC. In this case, all six methods consistently pick up sensitivity signals associated with the midlatitude trough, which has a strong impact on the TC movement and evolution $48 \mathrm{~h}$ after the observing time. Nevertheless, ETKF, ADSSV, and NCVAR all show another region of sensitivity to the east of the storm, probably in association with the strength of the western extent of the subtropical ridge, whereas the three types 


\section{\#38 WP14Shanshan $\mathrm{Ti}=20060914 \mathrm{Ta}=20060916$}

(a) ECMWF TESV

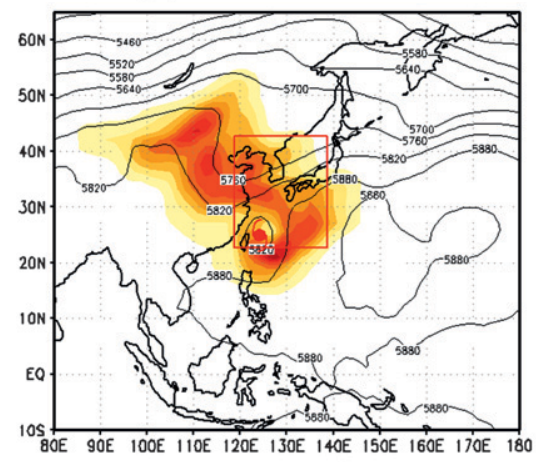

(d) ETKF

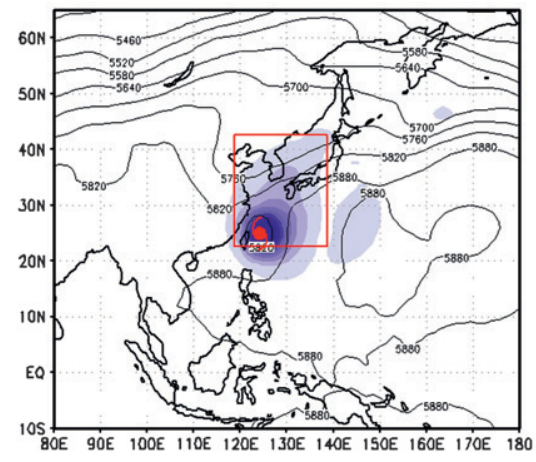

(b) NOGAPS TESV

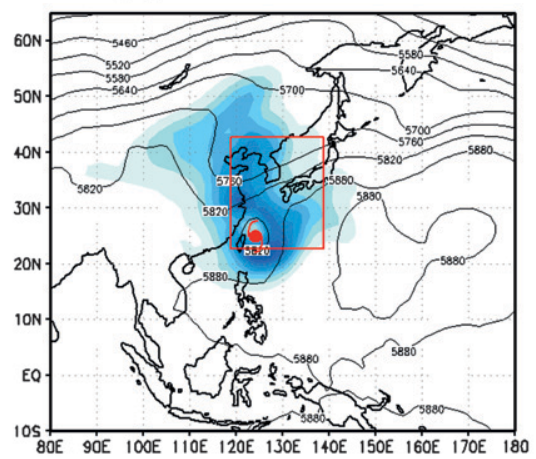

(e) MM5 ADSSV

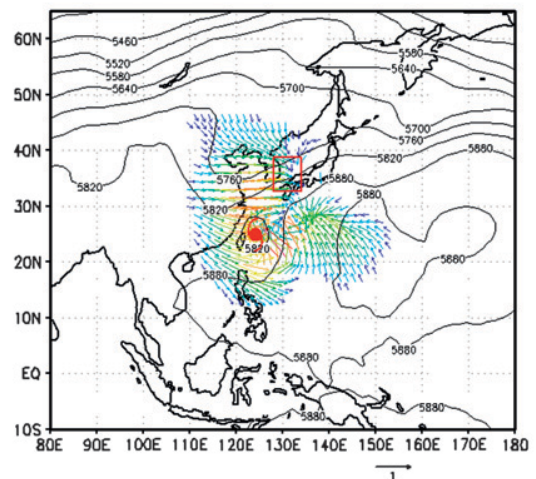

(c) JMA TESV

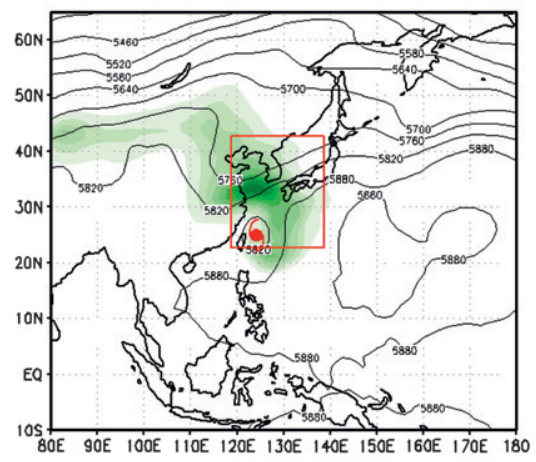

(f) NCEP DLM WIND VARIANCE

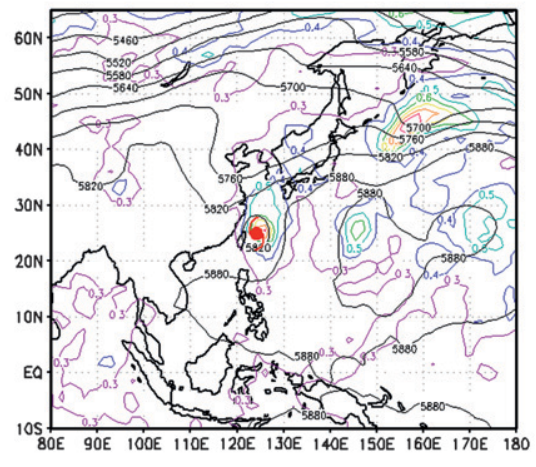

FIG. 11. As in Fig. 10, but for case 38 with 0000 UTC 16 Sep as the observing time.

of TESV also show the sensitivity information related to the subtropical high in this case.

\section{c. Case 66-Affected by the subtropical jet}

Typhoon Durian occurred very late into the typhoon season of 2006. The observing time $\left(t_{a}\right)$ for case 66 is 0000 UTC 28 November. From Fig. 12, it can be found that the gradient of the geopotential height field at $500 \mathrm{hPa}$ is relatively large at latitudes north of $20^{\circ} \mathrm{N}$. To highlight the location of the subtropical jet, the wind vectors (with wind speed higher than $20 \mathrm{~m} \mathrm{~s}^{-1}$ ) at $500 \mathrm{hPa}$ are superposed in Fig. 12. There are two main branches of the jet over East Asia. One is located at higher latitudes $\left(40^{\circ}-60^{\circ} \mathrm{N}\right)$ and may be associated with the polar front jet. Another is located at lower latitudes $\left(20^{\circ}-35^{\circ} \mathrm{N}\right)$ and is likely associated with the subtropical jet. The two jets merge to the east of $120^{\circ} \mathrm{E}$. At higher altitudes, such as $200 \mathrm{hPa}$ (figure not shown), only one jet is observed with a maximum wind speed of about $90 \mathrm{~m} \mathrm{~s}^{-1}$ near $30^{\circ} \mathrm{N}$. The above characteristics are consistent with the analysis of the subtropical jet in Krishnamurti (1961), which indicated that the subtropical jet usually occurs in winter in the Northern Hemisphere with the maximum wind around $70 \mathrm{~m} \mathrm{~s}^{-1}$ at $200 \mathrm{hPa}$ and the baroclinic zone above $500 \mathrm{hPa}$. Figures $12 \mathrm{a}-\mathrm{c}$ show that the TESV guidance appears in a belt zone along $20^{\circ}-30^{\circ} \mathrm{N}$, collocated with the southern (anticyclonic) side of the subtropical jet. ADSSV also shows a relatively short belt pattern of sensitivity at the southern edge of the jet. For ETKF, besides the maximum sensitivity around the TC, there is also a belt pattern located at $30^{\circ}-45^{\circ} \mathrm{N}$. However, this belt is more likely related to the midlatitude cyclone at lower levels (850-700 hPa, figure not shown). The sensitivity located at $40^{\circ} \mathrm{N}, 160^{\circ} \mathrm{E}$ of NCVAR is also associated with the midlatitude cyclone, which has no relationship with the TC evolution in this case. The dynamic interpretation of this sensitivity associated with the subtropical jet is not completely understood at this point and merits future research. 


\section{\#66 WP24Durian $\mathrm{Ti}=20061126 \mathrm{Ta}=20061128$}

(a) ECMWF TESV

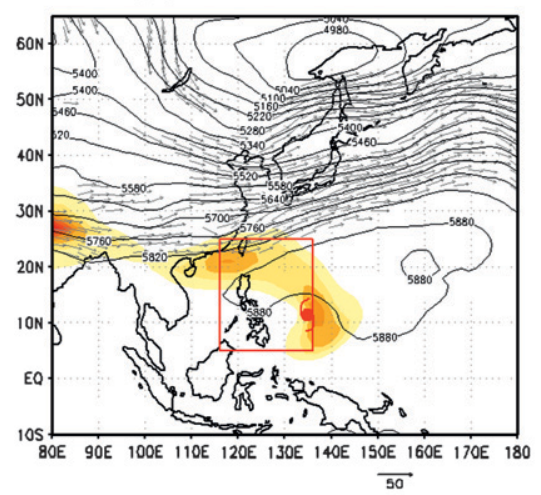

(d) ETKF

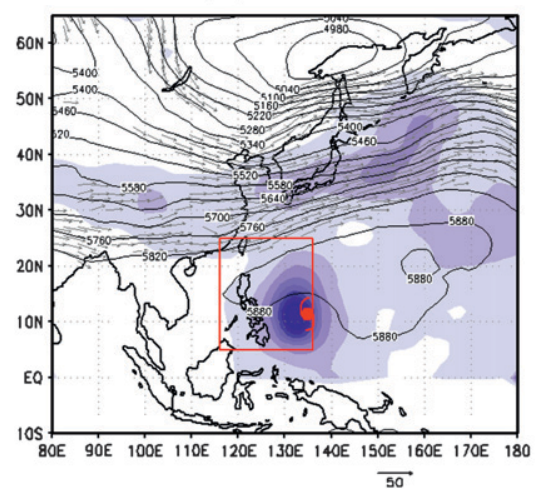

(b) NOGAPS TESV

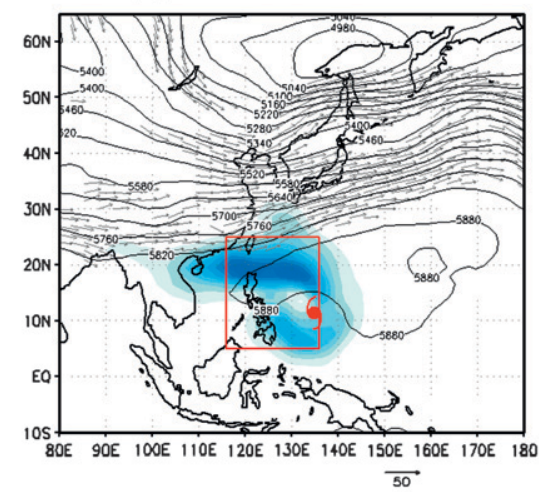

(e) MM5 ADSSV

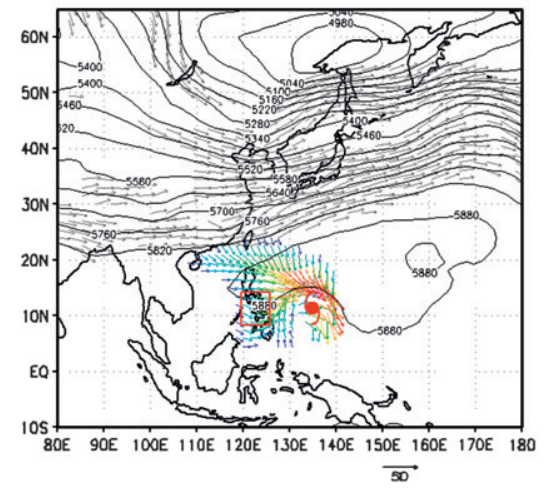

(c) JMA TESV

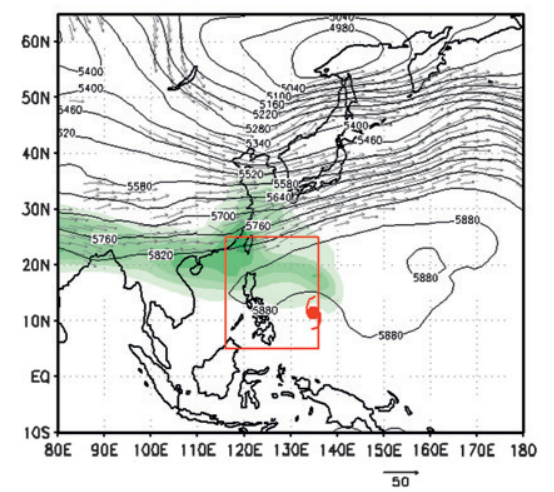

(f) NCEP DLM WIND VARIANCE

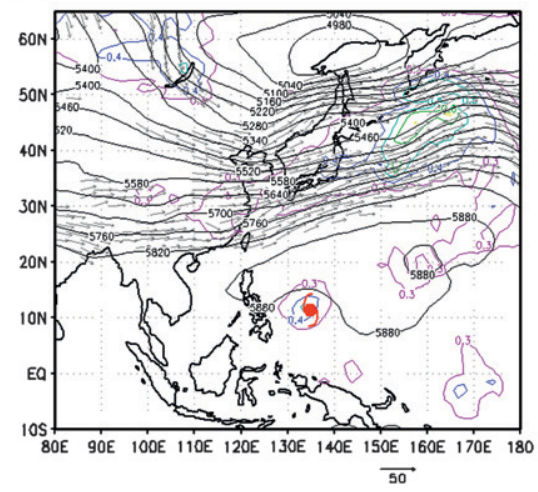

FIG. 12. As in Fig. 10, but for the sensitivities superposed with the geopotential height field (contour interval of 60 gpm) and wind field (vector; the scale is indicated by the arrow to the lower right) at $500 \mathrm{hPa}$ of case 66 with $0000 \mathrm{UTC} 28$ Nov as the observing time.

\section{Summary and future prospects}

The improvement of TC predictive skill through the assimilation of targeted observations is among one of the most important research and forecasting issues for TCs. To optimize the aircraft surveillance observations using dropwindsondes, and for future targeting using satellite and novel in situ observations, several targeted observing strategies have been developed and examined. The primary consideration in devising such strategies is to identify the sensitive areas in which the assimilation of targeted observations is expected to have the greatest influence on improving numerical forecasts. To highlight the unique features that affect the TCs over the northwestern Pacific, in this study, three TESVs from different global models (ECMWF, NOGAPS, and JMA/EPS), the ETKF based on multimodel ensemble members (ECMWF, NCEP/GEPS, and CMC), the NCEP/GEPS DLM wind variance, and the MM5 ADSSV are compared with each other (i.e., six different types of guidance with 15 comparison pairs) based on 84 cases of northwest Pacific TCs in 2006. The 84 cases consist of 19 TCs while multiple cases studying the same TCs are separated by $24 \mathrm{~h}$ on successive days. The values of the six types of guidance are interpolated to latitude-longitude $1.5^{\circ}$ grids and normalized by the maximum value of each method for each case.

The similarities among the six guidance products are evaluated by two objective statistical techniques as introduced in Majumdar et al. (2006) to show the diversity of the sensitivity regions in these products. In this study the statistical techniques of Majumdar et al. (2006) are further elaborated upon by employing varying threshold values. The range of different threshold values allows for an examination of the sensitivity of the comparison results with respect to the choice of the threshold values. We believe this provides a clearer and more detailed picture of the comparisons that that provided in Majumdar et al. (2006). The results show that the three TESVs are quite similar to one another in both the large 
and the small domains, especially regarding the comparison between ECSV and NGPSV. This is consistent with the findings in Majumdar et al. (2006) that the targeted methodology usually gives similar guidance irrespective of the model. Except for the comparison between NCVAR and ETKF, both of the statistical results show rather low similarities when NCVAR is compared with other targeted methods, especially on the synoptic scale (large domain). That is because the maximum sensitivity of NCVAR is usually located near the midlatitude jet or extratropical storm, where high winds may be collocated with large DLM wind variance or the baroclinity and related jet strength may allow for rapidly growing modes, which are probably captured by ETKF but may not be relevant to TC evolution. On the other hand, when focusing on the surveillance scale, the maximum sensitivity of NCVAR around the TC results in higher similarity when compared with the three TESVs and ADSSV in the small domain. In both the large and the small domains, ETKF and ADSSV show high similarity because their sensitivity results are usually close to the TC and in the TC itself. Meanwhile, higher similarities are found between ADSSV and the three TESVs methods as compared with those between ETKF and the TESVs especially in the large domain. This is primarily because ETKF tends to have high sensitivity uniformly distributed around the storm center as the highest error variance in the wind field corresponds to the spread in the location and structure of the TC in the ensemble. Furthermore, this large error variance always propagates into the verification region, since the verification region is chosen to be centered on the TC. Therefore, the assimilation of observations in the storm location is expected to reduce errors in the wind field associated with the storm at the verification time. Both ADSSV and TESVs often capture similar sensitivity patterns in particular areas around and outside of the storm center, thus leading to the higher similarity for the comparison of these two methods with ETKF.

Regarding the similarity of the guidance products for different TC intensities, the three TESVs have highest similarity to one another in the typhoon category (64-96 kt). As for the comparison between ETKF and other methods, no association is found between similarity and TC intensity. When comparing ADSSV with other methods, the highest similarities occur in the major typhoon category when compared with ECSV, NGPSV, and ETKF, but in the typhoon category when compared with JMASV and NCVAR. Generally speaking, more agreement among the guidance products exists for the stronger storms (MTY and TY) than for the weaker storms (TS). This finding is roughly consistent with the study of the Atlantic TCs (Majumdar et al. 2006), which found larger similarities for major hurricanes than for weaker storms.

There are several interesting dynamical systems affecting the TC motion ( Wu 2006) in the northwestern Pacific region, such as the subtropical high, the midlatitude trough, the subtropical jet, and the southwesterly monsoon. The latter two systems appear to play less significant roles in the Atlantic Ocean. In this study, we select three special cases to highlight not only the similarities and differences between different targeted methods but also to interpret them dynamically. The first case is affected by the subtropical high. In this case, the three TESVs and ADSSV show that major sensitivities are located to the east of the TC center by about $500 \mathrm{~km}$. The locations with the highest sensitivity collocate well with the border between the TC and the subtropical high. As shown in Wu et al. (2007a) and Peng and Reynolds (2006), such sensitivity patterns indicate that the steering effect of the subtropical high on storm movement and the sensitivity is almost always strongest on the side of the storm associated with the radial inflow. This is consistent with perturbation growth facilitated through changes to the steering flow of the storm and subsequent changes to the forecast track of the storm. The second case is affected by the midlatitude trough. In this case, all six methods consistently pick up the sensitivity signals associated with the midlatitude trough while the four adjoint methods (TESVs and ADSSV) produce high sensitivities at the center and the upstream region of the trough and the ensemble methods show sensitivity in the downstream region of the trough. The strong impact of the midlatitude trough to the movement and evolution of TC is well captured $48 \mathrm{~h}$ before the verification time. The third case is associated with the subtropical jet in the late typhoon season of 2006. The sensitivities of TESVs appear in a belt zone along the $20^{\circ}-30^{\circ} \mathrm{N}$, well collocated with the southern (anticyclonic) side of the subtropical jet. The ADSSV shows a relatively short belt pattern of sensitivity at the southern edge of the jet. The ETKF also shows a belt pattern located at $30^{\circ}-45^{\circ} \mathrm{N}$, but this is more likely related to a midlatitude cyclone at lower levels.

From the above analysis of the three cases, it is noted that the adjoint-based methods are more likely to capture the signals associated with the dynamic systems that may affect TC movement/evolution than the ensemble methods. Furthermore, an ensemble method including dynamic information and data assimilation information (i.e., ETKF) can provide more valuable information than a method that only considers the ensemble variance (i.e., NCVAR). 
Regarding other issues related to targeted observations, it is important to evaluate the influence of extra data based on the targeted guidance on the model forecast (Szunyogh et al. 2000, 2002). Kelly et al. (2007), Buizza et al. (2007), and Cardinali et al. (2007) designed a series of data denial experiments to evaluate the impact of targeted observational data on operational model forecast fields downstream. Their research is based on midlatitude systems. In contrast, the scientific basis behind how targeted observations influence forecasting of TC motion and structure remains unexplored. More work to assess the impact of the targeted data on TC forecasts is required.

Further research includes the interpretation of the dynamics of these targeting methods on a case-by-case basis (e.g., Wu et al. 2009). It is believed that results from this work would not only provide better insights into techniques, but also offer useful information to assist in targeted observations, especially for the DOTSTAR, Typhoon Hunting 2008 (TH08), and Tropical Cyclone Structure-2008 (TCS-08) associated with the THORPEXPacific Asian Regional Campaign (T-PARC) program conducted in the TC season of 2008, as well as the targeting of other data from satellites, radars, unmanned aircraft, and balloons.

Acknowledgments. The work is supported by the National Science Council of Taiwan through Grant NSC95-2119-M-002-039-MY2, the Office of Naval Research Grant N00014-05-1-0672, National Taiwan University Grant 97R0302, and the Central Weather Bureau Grant MOTC-CWB-96-6M-02. The authors thank the Japan Meteorological Agency for providing the 2006 typhoon track forecasting by the JAM Global Spectral Model, and JTWC for providing the track forecasts. Helpful comments from the anonymous reviewers are also appreciated. Melinda S. Peng and Carolyn A. Reynolds acknowledge the support of their sponsor, the Naval Research Laboratory, through Program Element $0601153 \mathrm{~N}$, and partial computer support provided by the Department of Defense Higher Performance Computing Program at NAVO MSRC.

\section{APPENDIX A}

\section{Summary of 84 Cases in Northwest Pacific 2006}

Table A1 lists the characteristics of the 84 cases used in this research. The names and annual numbers of TCs in the NW Pacific basin are shown under the column "name." Here WP stands for the northwest Pacific and $\mathrm{CP}$ for the central Pacific. Note that WP01 of case 1 is an unnamed tropical storm (TS). The model initial time $\left(t_{i}\right)$, observing (analysis) time $\left(t_{a}\right)$, and the verifying time $\left(t_{v}\right)$ are at 0000 UTC. For example, 0305 represents 0000 UTC 5 March 2006. The "verifying area" is $20^{\circ}$ by $20^{\circ}$ centered at the 96-h TC position forecast by the JTWC, which is valid at $t_{v}$ for the ETKF and three TESV methods (shown in the table). Note that for the ADSSV, the verifying area is different, which is defined as a box of $600 \mathrm{~km}$ by $600 \mathrm{~km}$ in Wu et al. (2007a). The northern, southern (in degrees $\mathrm{N}$ ), western and eastern (in degrees $\mathrm{E}$ ) peripheries of the verifying area are listed. The "intensity" indicates the 48 -h official forecast valid at $t_{a}$.

TABLE A1. Summary of the 84 cases used in this study.

\begin{tabular}{|c|c|c|c|c|c|c|c|c|c|}
\hline \multirow[b]{2}{*}{ No. } & \multirow[b]{2}{*}{ Name } & \multirow[b]{2}{*}{$t_{i}$} & \multirow[b]{2}{*}{$t_{a}$} & \multirow[b]{2}{*}{$t_{v}$} & \multicolumn{4}{|c|}{ Verifying area } & \multirow[b]{2}{*}{ Intensity (kt) } \\
\hline & & & & & $\mathrm{N}$ lat & $S$ lat & W lon & E lon & \\
\hline 1 & WP01TS & 0305 & 0307 & 0309 & 21.6 & 1.6 & 113.1 & 133.1 & 55 \\
\hline 2 & WP02 Chanchu & 0509 & 0511 & 0513 & 24.0 & 4.0 & 114.4 & 134.4 & 65 \\
\hline 3 & WP02 Chanchu & 0510 & 0512 & 0514 & 26.4 & 6.4 & 110.1 & 130.1 & 85 \\
\hline 4 & WP02 Chanchu & 0511 & 0513 & 0515 & 25.5 & 5.5 & 108.6 & 128.6 & 65 \\
\hline 5 & WP02 Chanchu & 0512 & 0514 & 0516 & 27.2 & 7.2 & 105.0 & 125.0 & 85 \\
\hline 6 & WP02 Chanchu & 0513 & 0515 & 0517 & 29.9 & 9.9 & 103.7 & 123.7 & 110 \\
\hline 7 & WP02 Chanchu & 0514 & 0516 & 0518 & 33.1 & 13.1 & 104.1 & 124.1 & 125 \\
\hline 8 & WP02 Chanchu & 0515 & 0517 & 0519 & 37.5 & 17.5 & 106.4 & 126.4 & 125 \\
\hline 9 & WP04 Ewiniar & 0701 & 0703 & 0705 & 28.0 & 8.0 & 121.9 & 141.9 & 90 \\
\hline 10 & WP04 Ewiniar & 0702 & 0704 & 0706 & 30.2 & 10.2 & 119.4 & 139.4 & 85 \\
\hline 11 & WP04 Ewiniar & 0703 & 0705 & 0707 & 32.5 & 12.5 & 118.4 & 138.4 & 100 \\
\hline 12 & WP04 Ewiniar & 0704 & 0706 & 0708 & 38.3 & 18.3 & 120.5 & 140.5 & 105 \\
\hline 13 & WP04 Ewiniar & 0705 & 0707 & 0709 & 41.6 & 21.6 & 121.3 & 141.3 & 100 \\
\hline 14 & WP04 Ewiniar & 0706 & 0708 & 0710 & 46.8 & 26.8 & 122.4 & 142.4 & 110 \\
\hline 15 & WP04 Ewiniar & 0707 & 0709 & 0711 & 50.4 & 30.4 & 122.6 & 142.6 & 90 \\
\hline 16 & WP05 Bilis & 0710 & 0712 & 0714 & 33.3 & 13.3 & 113.7 & 133.7 & 50 \\
\hline
\end{tabular}


TABLE A1. (Continued)

\begin{tabular}{|c|c|c|c|c|c|c|c|c|c|}
\hline \multirow[b]{2}{*}{ No. } & \multirow[b]{2}{*}{ Name } & \multirow[b]{2}{*}{$t_{i}$} & \multirow[b]{2}{*}{$t_{a}$} & \multirow[b]{2}{*}{$t_{v}$} & \multicolumn{4}{|c|}{ Verifying area } & \multirow[b]{2}{*}{ Intensity (kt) } \\
\hline & & & & & $\mathrm{N}$ lat & S lat & W lon & E lon & \\
\hline 17 & WP05 Bilis & 0711 & 0713 & 0715 & 34.8 & 14.8 & 110.7 & 130.7 & 70 \\
\hline 18 & WP05 Bilis & 0712 & 0714 & 0716 & 40.1 & 20.1 & 106.3 & 126.3 & 50 \\
\hline 19 & WP06 Kaemi & 0719 & 0721 & 0723 & 31.8 & 11.8 & 117.6 & 137.6 & 60 \\
\hline 20 & WP06 Kaemi & 0720 & 0722 & 0724 & 28.7 & 8.7 & 116.3 & 136.3 & 105 \\
\hline 21 & WP06 Kaemi & 0721 & 0723 & 0725 & 33.9 & 13.9 & 111.3 & 131.3 & 110 \\
\hline 22 & WP06 Kaemi & 0722 & 0724 & 0726 & 34.4 & 14.4 & 107.2 & 127.2 & 110 \\
\hline 23 & WP06 Kaemi & 0723 & 0725 & 0727 & 38.7 & 18.7 & 107.5 & 127.5 & 75 \\
\hline 24 & WP08 Saomai & 0806 & 0808 & 0810 & 34.7 & 14.7 & 115.7 & 135.7 & 75 \\
\hline 25 & WP08 Saomai & 0807 & 0809 & 0811 & 38.6 & 18.6 & 109.7 & 129.7 & 115 \\
\hline 26 & WP08 Saomai & 0808 & 0810 & 0812 & 38.0 & 18.0 & 104.4 & 124.4 & 90 \\
\hline 27 & WP09 Maria & 0806 & 0808 & 0810 & 46.5 & 26.5 & 121.8 & 141.8 & 55 \\
\hline 28 & WP10 Bopha & 0807 & 0809 & 0811 & 35.2 & 15.2 & 107.2 & 127.2 & 60 \\
\hline 29 & WP10 Bopha & 0808 & 0810 & 0812 & 34.0 & 14.0 & 104.6 & 124.6 & 35 \\
\hline 30 & WP10 Bopha & 0809 & 0811 & 0813 & 32.2 & 12.2 & 101.0 & 121.0 & 40 \\
\hline 31 & WP11 Wukong & 0813 & 0815 & 0817 & 50.9 & 30.9 & 125.7 & 145.7 & 65 \\
\hline 32 & WP11 Wukong & 0814 & 0816 & 0818 & 41.4 & 21.4 & 120.6 & 140.6 & 65 \\
\hline 33 & WP11 Wukong & 0815 & 0817 & 0819 & 43.3 & 23.3 & 122.2 & 142.2 & 70 \\
\hline 34 & WP11 Wukong & 0816 & 0818 & 0820 & 43.3 & 23.3 & 116.7 & 136.7 & 60 \\
\hline 35 & WP14 Shanshan & 0911 & 0913 & 0915 & 33.2 & 13.2 & 115.7 & 135.7 & 80 \\
\hline 36 & WP14 Shanshan & 0912 & 0914 & 0916 & 34.1 & 14.1 & 117.1 & 137.1 & 115 \\
\hline 37 & WP14 Shanshan & 0913 & 0915 & 0917 & 36.7 & 16.7 & 118.4 & 138.4 & 105 \\
\hline 38 & WP14 Shanshan & 0914 & 0916 & 0918 & 42.6 & 22.6 & 118.8 & 138.8 & 90 \\
\hline 39 & WP14 Shanshan & 0915 & 0917 & 0919 & 51.8 & 31.8 & 127.9 & 147.9 & 90 \\
\hline 40 & WP16 Yagi & 0918 & 0920 & 0922 & 30.3 & 10.3 & 137.3 & 157.3 & 75 \\
\hline 41 & WP16 Yagi & 0919 & 0921 & 0923 & 36.1 & 16.1 & 131.6 & 151.6 & 80 \\
\hline 42 & WP16 Yagi & 0920 & 0922 & 0924 & 43.3 & 23.3 & 133.5 & 153.5 & 130 \\
\hline 43 & WP16 Yagi & 0921 & 0923 & 0925 & 48.0 & 28.0 & 139.1 & 159.1 & 125 \\
\hline 44 & WP16 Yagi & 0922 & 0924 & 0926 & 51.7 & 31.7 & 156.5 & 176.5 & 100 \\
\hline 45 & WP18 Xangsane & 0926 & 0928 & 0930 & 26.6 & 6.6 & 110.0 & 130.0 & 60 \\
\hline 46 & WP18 Xangsane & 0927 & 0929 & 1001 & 26.2 & 6.2 & 101.3 & 121.3 & 85 \\
\hline 47 & WP18 Xangsane & 0928 & 0930 & 1002 & 25.3 & 5.3 & 96.0 & 116.0 & 115 \\
\hline 48 & WP19 Bebinca & 1003 & 1005 & 1007 & 33.9 & 13.9 & 124.5 & 144.5 & 60 \\
\hline 49 & WP19 Bebinca & 1004 & 1006 & 1008 & 34.1 & 14.1 & 125.9 & 145.9 & 65 \\
\hline 50 & WP21 Soulik & 1010 & 1012 & 1014 & 33.4 & 13.4 & 126.4 & 146.4 & 60 \\
\hline 51 & WP21 Soulik & 1011 & 1013 & 1015 & 33.8 & 13.8 & 127.7 & 147.7 & 80 \\
\hline 52 & WP21 Soulik & 1012 & 1014 & 1016 & 37.7 & 17.7 & 131.1 & 151.1 & 75 \\
\hline 53 & WP21 Soulik & 1013 & 1015 & 1017 & 46.8 & 26.8 & 142.1 & 162.1 & 95 \\
\hline 54 & WP21 Soulik & 1014 & 1016 & 1018 & 48.8 & 28.8 & 155.8 & 175.8 & 75 \\
\hline 55 & WP22 Cimaron & 1027 & 1029 & 1031 & 26.7 & 6.7 & 107.4 & 127.4 & 65 \\
\hline 56 & WP22 Cimaron & 1028 & 1030 & 1101 & 26.2 & 6.2 & 103.9 & 123.9 & 85 \\
\hline 57 & WP22 Cimaron & 1029 & 1031 & 1102 & 25.8 & 5.8 & 102.4 & 122.4 & 90 \\
\hline 58 & WP22 Cimaron & 1030 & 1101 & 1103 & 26.1 & 6.1 & 99.5 & 119.5 & 90 \\
\hline 59 & WP22 Cimaron & 1031 & 1102 & 1104 & 26.3 & 6.3 & 96.6 & 116.6 & 90 \\
\hline 60 & WP22 Cimaron & 1101 & 1103 & 1105 & 30.4 & 10.4 & 101.1 & 121.1 & 65 \\
\hline 61 & WP22 Cimaron & 1102 & 1104 & 1106 & 29.5 & 9.5 & 106.6 & 126.6 & 45 \\
\hline 62 & WP23 Chebi & 1110 & 1112 & 1114 & 24.0 & 4.0 & 105.3 & 125.3 & 50 \\
\hline 63 & WP23 Chebi & 1111 & 1113 & 1115 & 27.4 & 7.4 & 99.7 & 119.7 & 90 \\
\hline 64 & WP23 Chebi & 1112 & 1114 & 1116 & 29.6 & 9.6 & 98.7 & 118.7 & 65 \\
\hline 65 & WP23 Chebi & 1113 & 1115 & 1117 & 30.9 & 10.9 & 98.8 & 118.8 & 45 \\
\hline 66 & WP24 Durian & 1126 & 1128 & 1130 & 25.0 & 5.0 & 116.0 & 136.0 & 95 \\
\hline 67 & WP24 Durian & 1127 & 1129 & 1201 & 25.4 & 5.4 & 111.4 & 131.4 & 100 \\
\hline 68 & WP24 Durian & 1128 & 1130 & 1202 & 26.7 & 6.7 & 112.7 & 132.7 & 105 \\
\hline 69 & WP24 Durian & 1129 & 1201 & 1203 & 26.5 & 6.5 & 108.4 & 128.4 & 105 \\
\hline 70 & WP24 Durian & 1130 & 1202 & 1204 & 25.6 & 5.6 & 106.5 & 126.5 & 85 \\
\hline 71 & WP24 Durian & 1201 & 1203 & 1205 & 22.9 & 2.9 & 99.6 & 119.6 & 45 \\
\hline 72 & WP24 Durian & 1202 & 1204 & 1206 & 21.3 & 1.3 & 96.2 & 116.2 & 45 \\
\hline 73 & WP25 Utor & 1208 & 1210 & 1212 & 23.1 & 3.1 & 105.2 & 125.2 & 50 \\
\hline 74 & WP25 Utor & 1209 & 1211 & 1213 & 24.0 & 4.0 & 103.9 & 123.9 & 90 \\
\hline
\end{tabular}


TABLE A1. (Continued)

\begin{tabular}{rrrrrrrrrr}
\hline \hline & & & & \multicolumn{5}{c}{ Verifying area } \\
\cline { 6 - 8 } No. & Name & $t_{i}$ & $t_{a}$ & $t_{v}$ & $\mathrm{~N}$ lat & S lat & W lon & E lon & Intensity (kt) \\
\hline 75 & WP25 Utor & 1210 & 1212 & 1214 & 26.5 & 6.5 & 100.9 & 120.9 & 135 \\
76 & WP25 Utor & 1211 & 1213 & 1215 & 26.8 & 6.8 & 102.2 & 122.2 & 85 \\
77 & WP25 Utor & 1212 & 1214 & 1216 & 26.8 & 6.8 & 100.2 & 120.2 & 55 \\
78 & CP01 Ioke & 0828 & 0830 & 0901 & 32.7 & 12.7 & 152.3 & 172.3 & 125 \\
79 & CP01 Ioke & 0829 & 0831 & 0902 & 33.9 & 13.9 & 150.1 & 170.1 & 130 \\
80 & CP01 Ioke & 0830 & 0901 & 0903 & 34.0 & 14.0 & 145.7 & 165.7 & 130 \\
81 & CP01 Ioke & 0831 & 0902 & 0904 & 35.6 & 15.6 & 140.6 & 160.6 & 125 \\
82 & CP01 Ioke & 0901 & 0903 & 0905 & 37.7 & 17.7 & 133.5 & 153.5 & 115 \\
83 & CP01 Ioke & 0902 & 0904 & 0906 & 41.6 & 21.6 & 133.2 & 153.2 & 110 \\
84 & CP01 Ioke & 0903 & 0905 & 0907 & 53.8 & 33.8 & 141.5 & 161.5 & 80 \\
\hline
\end{tabular}

\section{APPENDIX B}

\section{The Size of the Square Region for the Ranking of Neighboring Regions}

The size of the square regions should be sufficiently large so that the values in adjacent regions are not strongly correlated (Majumdar et al. 2006). Based on 84 cases, the correlations for the six methods at different distances are computed by first setting $Y=286$ square regions containing $3 \times 3$ grid points at $150-\mathrm{km}$ resolution within each region. For each method, the correlation coefficient between any two square regions is calculated by

$$
r=\frac{S_{x y}}{S_{x} S_{y}} .
$$

Here, $S_{x}$ and $S_{y}$ are the standard deviations of the average values within these two square regions of the 84 cases, and $S_{x y}$ is their covariance. The definitions of $S_{x}, S_{y}$, and $S_{x y}$ are

$$
\begin{aligned}
& S_{x}=\frac{1}{n-1} \sqrt{\sum_{i=1}^{n}\left(x_{i}-\bar{x}\right)^{2}}, \\
& S_{y}=\frac{1}{n-1} \sqrt{\sum_{i=1}^{n}\left(y_{i}-\bar{y}\right)^{2}},
\end{aligned}
$$

and

$$
S_{x y}=\frac{1}{n-1} \sum_{i=1}^{n}\left(x_{i}-\bar{x}\right)\left(y_{i}-\bar{y}\right)
$$

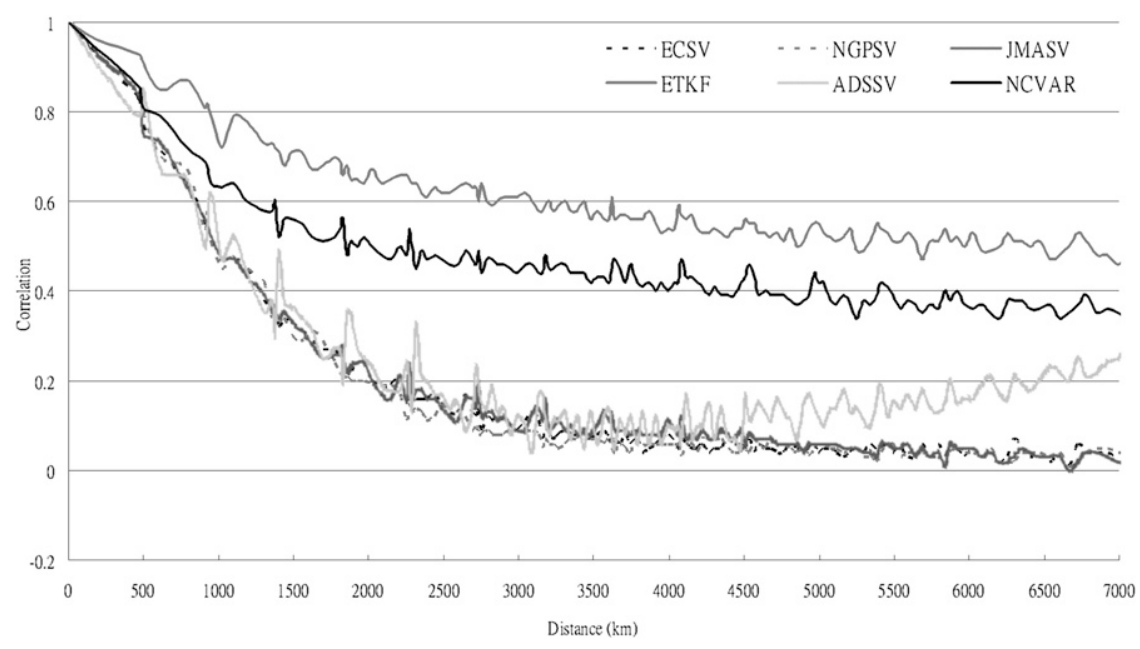

FIG. B1. Correlation between points as the function of distance among all regions for the six targeted methods. 
with $n=84, x$ and $y$ are the values (average over the $3 \times 3$ grid points) in these two square regions for each case, and $\bar{x}$ and $\bar{y}$ are the mean values of $x$ and $y$ for all 84 cases. Therefore, the correlation coefficient can be represented by the following function:

$$
r=\frac{\sum_{i=1}^{n}\left(x_{i}-\bar{x}\right)\left(y_{i}-\bar{y}\right)}{\sqrt{\sum_{i=1}^{n}\left(x_{i}-\bar{x}\right)^{2}} \sqrt{\sum_{i=1}^{n}\left(y_{i}-\bar{y}\right)^{2}}},
$$

whose value is between -1 and 1 .

There are 40755 combinations between any two of the 286 square regions. The 40755 correlation coefficients and their corresponding distances can be shown in Fig. B1, which shows the smoothed curve representing the correlations as the function of distance among all regions for the six targeted methods. When the distance is shorter than $4000 \mathrm{~km}$, all methods show a decreasing correlation. However, beyond $4000 \mathrm{~km}$, ADSSV shows an increasing correlation. It means that the sensitivities of ADSSV are usually located closer to the TC than other methods. It is also found that for three TESVs and ADSSV, the corresponding distance is around $1000 \mathrm{~km}$ for a correlation coefficient of 0.5 , a threshold smaller than which the two square regions appears more independent. However, for ETKF and NCVAR, the correlation coefficients are larger. That is because the distributions of sensitivities are more random for these two methods than for the other methods. Based on Fig. B1, in this study, $1000 \mathrm{~km}$ is adopted as the distance between two regions for the ranking of neighboring regions test.

\section{REFERENCES}

Aberson, S. D., 2002: Two years of hurricane synoptic surveillance. Wea. Forecasting, 17, 1101-1110.

_ 2003: Targeted observations to improve operational tropical cyclone track forecast guidance. Mon. Wea. Rev., 131, 1613-1628.

_ 2008: Large forecast degradations due to synoptic surveillance during the 2004 and 2005 hurricane seasons. Mon. Wea. Rev., 136, 3138-3150.

_ , and J. L. Franklin, 1999: Impact on hurricane track and intensity forecast of GPS dropsonde observations from the firstseason flights of the NOAA Gulfstream-IV jet aircraft. Bull. Amer. Meteor. Soc., 80, 421-427.

Bishop, C. H., B. J. Etherton, and S. J. Majumdar, 2001: Adaptive sampling with the ensemble transform Kalman filter. Part I: Theoretical aspects. Mon. Wea. Rev., 129, 420-436.

Buizza, R., 1994: Localization of optimal perturbations using a projection operator. Quart. J. Roy. Meteor. Soc., 120, 1647-1681.

_ , and A. Montani, 1999: Targeted observations using singular vectors. J. Atmos. Sci., 56, 2965-2985.

—, C. Cardinali, G. Kelly, and J.-N. Thépaut, 2007: The value of observations. II: The value of observations located in singular- vector-based target areas. Quart. J. Roy. Meteor. Soc., 133, 1817-1832.

Cardinali, C., R. Buizza, G. Kelly, M. Shapiro, and J.-N. Thépaut, 2007: The value of observations. III: Influence of weather regimes on targeting. Quart. J. Roy. Meteor. Soc., 133, 1833-1842.

Chou, K.-H., and C.-C. Wu, 2008: Development of the typhoon initialization in a mesoscale model-Combination of the bogused vortex with the dropwindsonde data in DOTSTAR. Mon. Wea. Rev., 136, 865-879.

Gelaro, R., T. E. Rosmond, and R. Daley, 2002: Singular vector calculations with an analysis error variance metric. Mon. Wea. Rev., 130, 1166-1186.

Grell, G. A., J. Dudhia, and D. R. Stauffer, 1995: A description of the fifth generation Penn State/NCAR Mesoscale Model (MM5). NCAR Tech. Note NCAR/TN-398+STR, 122 pp.

Joly, A., and Coauthors, 1997: The Fronts and Atlantic StormTrack Experiment (FASTEX): Scientific objectives and experimental design. Bull. Amer. Meteor. Soc., 78, 1917-1940.

Kelly, G., J.-N. Thépaut, R. Buizza, and C. Cardinali, 2007: The value of observations. I: Data denial experiments for the Atlantic and the Pacific. Quart. J. Roy. Meteor. Soc., 133, 1803-1815.

Krishnamurti, T. N., 1961: The subtropical jet stream of the winter. J. Atmos. Sci., 18, 172-191.

Langland, R. H., and N. L. Baker, 2004: Estimation of observation impact using the NRL atmospheric variational data assimilation system. Tellus, 56A, 189-201. , and Coauthors, 1999: The North Pacific Experiment, NORPEX-98: Targeted observations for improved North American weather forecasts. Bull. Amer. Meteor. Soc., 80, 1363-1384.

Leutbecher, M., 2003: A reduced rank estimate of forecast error variance changes due to intermittent modifications of the observing network. J. Atmos. Sci., 60, 729-742.

Mahfouf, J.-F., and F. Rabier, 2000: The ECMWF operational implementation of four-dimensional variational assimilation. Part II: Experimental results with improved physics. Quart. J. Roy. Meteor. Soc., 126, 1171-1190.

Majumdar, S. J., C. H. Bishop, B. J. Etherton, and Z. Toth, 2002a: Adaptive sampling with the ensemble transform Kalman filter. Part II: Field program implementation. Mon. Wea. Rev., 130, 1356-1369.

$\longrightarrow,-$ R. Buizza, and R. Gelaro, 2002b: A comparison of ensemble-transform Kalman-filter targeting guidance with ECMWF and NRL total-energy singular-vector guidance. Quart. J. Roy. Meteor. Soc., 128, 2527-2549.

- S. D. Aberson, C. H. Bishop, R. Buizza, M. S. Peng, and C. A. Reynolds, 2006: A comparison of adaptive observing guidance for Atlantic tropical cyclones. Mon. Wea. Rev., 134, 2354-2372.

Palmer, T. N., R. Gelaro, J. Barkmeijer, and R. Buizza, 1998: Singular vectors, metrics, and adaptive observations. J. Atmos. Sci., 55, 633-653.

Peng, M. S., and C. A. Reynolds, 2006: Sensitivity of tropical cyclone forecasts as revealed by singular vectors. J. Atmos. Sci., 63, 2508-2528.

Reynolds, C. A., M. S. Peng, S. J. Majumdar, S. D. Aberson, C. H. Bishop, and R. Buizza, 2007: Interpretation of adaptive observing guidance for Atlantic tropical cyclones. Mon. Wea. Rev., 135, 4006-4029.

Rosmond, T. E., 1997: A technical description of the NRL adjoint model system. NRL/MR/7532/97/7230, Naval Research Laboratory, Monterey, CA, $62 \mathrm{pp}$. 
Szunyogh, I., Z. Toth, R. E. Morss, S. J. Majumdar, B. J. Etherton, and C. H. Bishop, 2000: The effect of targeted dropsonde observations during the 1999 Winter Storm Reconnaissance Program. Mon. Wea. Rev., 128, 3520-3537.

- $\longrightarrow$ A. V. Zimin, S. J. Majumdar, and A. Persson, 2002: Propagation of the effect of targeted observations: The 2000 Winter Storm Reconnaissance Program. Mon. Wea. Rev., 130, 1144-1165.

Toth, Z., and E. Kalnay, 1993: Ensemble forecasting at NMC: The generation of perturbations. Bull. Amer. Meteor. Soc., 74, 2317-2330.

Wei, M., Z. Toth, R. Wobus, and Y. Zhu, 2008: Initial perturbations based on the ensemble transform (ET) technique in the NCEP global operational forecast system. Tellus, $60 \mathbf{A}$, 62-79.

Wilks, D. S., 1995: Statistical Methods in the Atmospheric Sciences. Academic Press, 467 pp.

Wu, C.-C., 2006: Targeted observation and data assimilation for tropical cyclone track prediction. Proc. Sixth Int. Workshop on Tropical Cyclones, San Jose, Costa Rica, WMO/CAS/ WWW, 409-423.

, T.-S. Huang, W.-P. Huang, and K.-H. Chou, 2003: A new look at the binary interaction: Potential vorticity diagnosis of he unusual southward movement of Typhoon Bopha (2000) and its interaction with Typhoon Saomai (2000). Mon. Wea. Rev., 131, 1289-1300.

— , and Coauthors, 2005: Dropwindsonde Observations for Typhoon Surveillance near the Taiwan Region (DOTSTAR): An overview. Bull. Amer. Meteor. Soc., 86, 787-790.

—, J.-H. Chen, P.-H. Lin, and K.-H. Chou, 2007a: Targeted observations of tropical cyclone movement based on the adjoint-derived sensitivity steering vector. J. Atmos. Sci., 64, 2611-2626.

—, K.-H. Chou, P.-H. Lin, S. D. Aberson, M. S. Peng, and T. Nakazawa, 2007b: The impact of dropwindsonde data on typhoon track forecasts in DOTSTAR. Wea. Forecasting, 22, 1157-1176.

—, S.-G. Chen, J.-H. Chen, K.-H. Chou, and P.-H. Lin, 2009: Interaction of Typhoon Shanshan (2006) with the midlatitude trough from both adjoint-derived sensitivity steering vector and potential vorticity perspectives. Mon. Wea. Rev., 137, 852-862.

Yamaguchi, M., T. Iriguchi, T. Nakazawa, and C.-C. Wu, 2009: An observing system experiment for Typhoon Conson (2004) using a singular vector method and DOTSTAR data. Mon. Wea. Rev., in press. 